NATIONAL LABORATORY

\title{
Independent Validation and Verification of Process Design and Optimization Technology Diagnostic and Control of Natural Gas Fired Furnaces via Flame Image Analysis Technology
}

May 2009

Prepared by

Daryl Cox

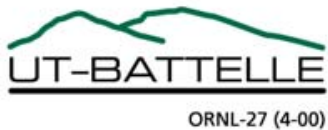




\title{
DOCUMENT AVAILABILITY
}

Reports produced after January 1, 1996, are generally available free via the U.S. Department of Energy (DOE) Information Bridge.

Web site http://www.osti.gov/bridge

Reports produced before January 1, 1996, may be purchased by members of the public from the following source.

\author{
National Technical Information Service \\ 5285 Port Royal Road \\ Springfield, VA 22161 \\ Telephone 703-605-6000 (1-800-553-6847) \\ TDD 703-487-4639 \\ Fax 703-605-6900 \\ E-mail info@ntis.gov \\ Web site http://www.ntis.gov/support/ordernowabout.htm
}

Reports are available to DOE employees, DOE contractors, Energy Technology Data Exchange (ETDE) representatives, and International Nuclear Information System (INIS) representatives from the following source.

Office of Scientific and Technical Information

P.O. Box 62

Oak Ridge, TN 37831

Telephone 865-576-8401

Fax 865-576-5728

E-mail reports@osti.gov

Web site http://www.osti.gov/contact.html

This report was prepared as an account of work sponsored by an agency of the United States Government. Neither the United States Government nor any agency thereof, nor any of their employees, makes any warranty, express or implied, or assumes any legal liability or responsibility for the accuracy, completeness, or usefulness of any information, apparatus, product, or process disclosed, or represents that its use would not infringe privately owned rights. Reference herein to any specific commercial product, process, or service by trade name, trademark, manufacturer, or otherwise, does not necessarily constitute or imply its endorsement, recommendation, or favoring by the United States Government or any agency thereof. The views and opinions of authors expressed herein do not necessarily state or reflect those of the United States Government or any agency thereof. 
ORNL/TM-2009/119

\section{OAK RIDGE NATIONAL LABORATORY}

\section{Independent Validation and Verification of Process Design and Optimization Technology Diagnostic and Control of Natural Gas Fired Furnaces via Flame Image Analysis Technology}

Date Published: May 2009

Prepared by Oak Ridge National Laboratory

P.O. Box 2008, Oak Ridge, Tennessee 37831-6285

managed by UT-Battelle, LLC, for the U.S. Department of Energy under contract DE-AC05-00OR22725.

The submitted manuscript has been authored by a contractor of the U.S. Government under contract DE-AC05-00OR22725. Accordingly, the U.S. Government retains a nonexclusive, royalty-free license to publish or reproduce the published form of this contribution, or allow others to do so, for U.S.

Government purposes. 



\section{Table of Contents}

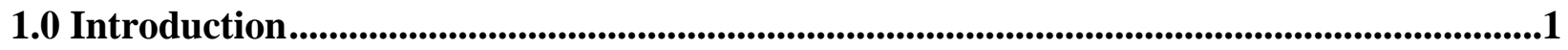

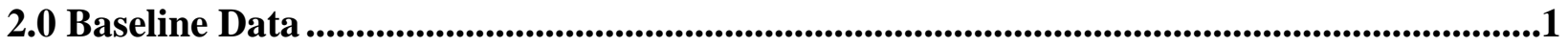

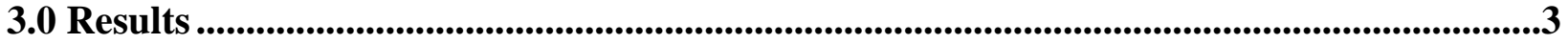

Appendix A.

Summary Report Submitted by Environ International Corporation, July 30, 2008

Appendix B.

Test Summary from Enterprise Energy and Research, July 2008 


\subsection{Introduction}

The United States Department of Energy, Industrial Technologies Program has invested in emerging Process Design and Optimizations Technologies (PDOT) to encourage the development of new initiatives that might result in energy savings in industrial processes.

Gas fired furnaces present a harsh environment, often making accurate determination of correct air/fuel ratios a challenge. Operation with the correct air/fuel ratio and especially with balanced burners in multi-burner combustion equipment can result in improved system efficiency, yielding lower operating costs and reduced emissions.

Flame Image Analysis offers a way to improve individual burner performance by identifying and correcting fuel-rich burners. ${ }^{1}$ The anticipated benefit of this technology is improved furnace thermal efficiency, and lower NOx emissions.

Independent validation and verification $(\mathrm{V} \& \mathrm{~V})$ testing of the FIA technology was performed at Missouri Forge, Inc., in Doniphan, Missouri by Environ International Corporation (V\&V contractor) and Enterprise Energy and Research (EE\&R) ${ }^{2}$, the developer of the technology. The test site was selected by the technology developer and accepted by Environ after a meeting held at Missouri Forge. As stated in the solicitation for the V\&V contractor, "The objective of this activity is to provide independent verification and validation of the performance of this new technology when demonstrated in industrial applications. A primary goal for the $\mathrm{V} \& \mathrm{~V}$ process will be to independently evaluate if this technology, when demonstrated in an industrial application, can be utilized to save a significant amount of the operating energy cost. The Seller will also independently evaluate the other benefits of the demonstrated technology that were previously identified by the developer, including those related to product quality, productivity, environmental impact, etc."3

A test plan was provided by the technology developer and is included as an appendix to the summary report submitted by Environ (Appendix A). That plan required the V\&V contractor to:

- Establish the as-found furnace operating conditions.

- Tune the furnace using currently available technology to establish baseline conditions.

- Tune the furnace using the FIA technology.

- Document the improved performance that resulted from application of the FIA technology.

It is important to note that the testing was not designed to be a competition or comparison between two different methodologies that could be used for furnace tuning. Rather, the intent was to quantify improvements in furnace performance that could not be achieved with existing technology. Therefore, the measure of success is improvement beyond the furnace efficiency obtainable using existing furnace optimization methods rather than improvement from the as found condition.

\footnotetext{
${ }^{1}$ Shahla Keyvan, Diagnostics and Control of Natural Gas Fired Furnaces via Flame Image Analysis, FY03 Sensors and Automation Review Meeting

${ }^{2}$ At the beginning of the project the technology developer was associated with the University of Missouri Columbia (UMC). Prior to the conclusion of the test this affiliation was changed to Energy Enterprise and Research (EE\&R).

${ }^{3}$ Subcontract 4000054341, Page 3, Section C-Statement of Work
} 


\subsection{Baseline Data}

The furnace selected for the V\&V testing was a manually-controlled natural gas fired heattreating furnace operated in batch mode. Load consistency was established by heat-treating a batch of transmission shafts each time. The process required operating the furnace at full-fire for the first hour to bring the load up to temperature, followed by one hour for temperature stabilization and one hour to "soak" at temperature. Fuel consumption, temperature, and flue gas composition and temperature were recorded with portable data acquisition equipment.

The first sets of data collected were used to establish furnace performance as normally operated by Missouri Forge. Eight sets of data were collected and averaged to establish fuel consumption for each hour of operation (Table 1). Two alternate conditions were examined to determine the effect of controlling excess air on furnace operation. Run 9 kept the manual air damper in the $40 \%$ open position, consistent with normal furnace operation while manually controlling fuel flow to reduce burner cycling. Run 10 incorporated automatic operation for hour one and reduced air flow and manual control of the fuel flow for hours two and three.

There was little change in fuel consumption between the baseline data collected and Run 9, which did not attempt to control combustion air flow. However, there was a $15 \%$ decrease in fuel consumption between the baseline data and Run 10, where first-hour operation was not changed and hours two and three employed reduced combustion air and manual fuel control. Therefore, it was determined that relative to the normal operating conditions at Missouri Forge a $15 \%$ reduction in fuel consumption was possible by adjusting combustion air and manually controlling fuel flow during the last two hours of the batch.

Product compliance with contract requirements for quality was confirmed through testing performed by Missouri Forge personnel, as noted in Section 6.3 of Appendix A. Subsequent to baseline testing and furnace tuning, data were collected using the Flame Image Analysis system to establish improvements in furnace operation based on use of FIA technology.

Table 1-Energy Consumption, MMBtu

\begin{tabular}{|c|c|c|c|c|c|c|}
\hline Run & Description & Hour 1 & Hour 2 & Hour 3 & Total & $\begin{array}{c}\text { Change } \\
\text { from } \\
\text { baseline, } \\
\%\end{array}$ \\
\hline $1-8$ & Baseline, avg. & 1.552 & 0.955 & 0.757 & 3.264 & - \\
\hline 9 & $\begin{array}{l}\text { Baseline run, manual fuel flow control, } \\
40 \% \text { damper }\end{array}$ & 1.565 & 0.939 & 0.741 & 3.245 & -0.58 \\
\hline 10 & $\begin{array}{l}\text { Auto operation hour } 1 \text {, reduced air and } \\
\text { manual fuel flow control hrs } 2 \text { and } 3\end{array}$ & 1.552 & 0.689 & 0.515 & 2.757 & -15.53 \\
\hline 11 & $\begin{array}{l}\text { Baseline run, new furnace controller, } \\
40 \% \text { damper }\end{array}$ & 1.556 & 0.976 & 0.734 & 3.265 & 0.03 \\
\hline 12 & $\begin{array}{l}\text { Optimized run w/new controller, } 25 \% \\
\text { damper hr 1, } 12.5 \% \text { damper hrs } 2 \& 3\end{array}$ & 1.464 & 0.820 & 0.651 & 2.934 & -10.11 \\
\hline
\end{tabular}


On November 28 and 29, 2007 EE\&R personnel installed the FIA system on the furnace at Missouri Forge. EE\&R had visited the site on previous occasions and had already established a damper position of $25 \%$ as optimal. In accordance with the test plan flame image analysis would be conducted starting twenty minutes before the end of the high-fire period and twenty minutes before the end of the soak period ( $\mathrm{T}=40 \mathrm{~min}$ and $\mathrm{T}=160 \mathrm{~min}$ ). The manual damper would be adjusted through five settings, dwelling approximately five seconds at each setting.

\subsection{Results}

As a result of the data collected during the test, the V\&V contractor determined that the Flame Image Analysis system did not improve the efficiency of the furnace beyond the values established during baseline testing. The system only produced efficiency gains compatible with traditional methodologies. Since the goal was to show improvement beyond existing methods of furnace tuning, the Flame Image Analysis system did not meet the objective. Since the FIA technology requires considerably more time to configure for testing, requires constant cooling to prevent damage from the furnace, and utilizes components with significant cost, the economic benefit of this technology was not established by this series of tests.

It should be noted the effect of the particular furnace configuration and condition, the method of combustion air control, or the burner arrangement on the results of the test is unclear. However, the facility was chosen by the technology developer so it is expected that these items would have minimal effect on the outcome of the test. Also, the test plan was written by the technology developer to avoid the possibility of test methods having a negative impact on the test.

Details of the test are included as Appendix A to this report, including data summaries, graphs, and tables. EE\&R supplied a response to the final report by Environ and it is included as Appendix B. The response disagrees with Environ's finding that the FIA system did not adequately demonstrate improvement over traditional methods of furnace tuning. The source of the disagreement lays in the baseline performance values. EE\&R considers the starting point to be the as found condition of the furnace (prior to any optimization) rather than the values determined by Environ as part of the baseline testing. However, this is in conflict with the established scope of the testing.

It should be noted that this report makes no conclusions about the efficacy of FIA technology when applied to furnaces with different configurations or when tested in different manners. The conclusions only relate to the specific testing done at Missouri Forge following the test plan written by EE\&R. 

Appendix A

Summary Report Submitted by Environ International Corporation July 30, 2008 



\title{
Validation and Verification Testing of UMC's Flame Image Analysis System
}

\author{
Report prepared for: \\ U.S. Department of Energy \\ Industrial Technologies Program \\ and \\ Oak Ridge National Laboratory
}

Report prepared by:

ENVIRON International Corporation

8 Hollis Street

Groton, MA 01450

July 30, 2008

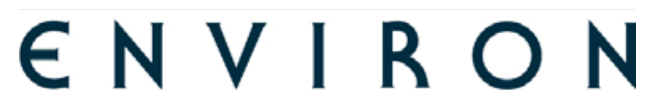




\section{Executive Summary}

The Department of Energy, through the Industrial Technologies Program, has supported the development of a novel technology for control of industrial combustion systems. This work has been conducted by a team from the University of Missouri-Columbia (UMC), led by Professor Shahla Keyvan. Their Flame Image Analysis System (FIA) consists of a video camera mounted in a water-cooled housing. Advanced image analysis and artificial intelligence techniques are applied to analyze flame images. These diagnostics can be executed in real time using a notebook computer. The potential benefits claimed by the developer include improved thermal efficiency, reduced $\mathrm{NO}_{\mathrm{x}}$ emissions, increased productivity, and improved product quality.

In October of 2006, the DOE awarded a contract to ENVIRON to verify and validate the FIA system through independent monitoring of a field trial. The specific goal of the project was to independently evaluate the capability of the UMC FIA system to provide information which would enable energy savings to be achieved in industrial furnaces.

UMC arranged for these tests to be conducted at a commercial heat treating facility located in Missouri. A natural-gas-fired, batch heat-treating furnace at this site was equipped by ENVIRON with instrumentation necessary to monitor energy consumption and to measure flue gas composition. All tests were conducted with identical furnace loads: transmission shafts for the automotive industry.

In an initial set of baseline tests, the furnace energy consumption was carefully characterized by ENVIRON during normal production operations. Furnace excess air levels were found to be relatively high and it was clear that energy savings could be obtained by reducing the amount of excess air. In a second set of baseline runs, the benefits of lower excess air operation were quantified through optimization using conventional flue gas analysis techniques. Energy consumption was reduced by about $15 \%$.

In a third set of runs, the FIA system was installed on the furnace and operated by UMC staff. Evaluation of the FIA system was conducted following a test plan prepared by UMC. This system was evaluated at all phases of furnace operation and over a wide range of excess air levels. As stated in the UMC test plan, it was anticipated that the FIA system would "show and select the optimum air flow". Although provided with many opportunities, the operators of the system were unable to detect optimum conditions based on their flame analyses. Consequently, no energy efficiency benefit relating to use of the FIA system could be assessed. Differences between FIA signals for the furnace's two burners, when they were deliberately put out of balance, were observed. However, it was not clear from this demonstration that the FIA system could yield adequate sensitivity to effectively balance multi-burner furnaces.

Based this verification and validation testing, it can only be concluded that the FIA system, as currently configured and operated, offers no benefit to operators of similar furnaces. If the FIA system can be improved to yield the claimed benefits regarding identification of energy efficiency improvements, conventional methods of furnace 
efficiency optimization could still present a challenge to this new technology in the industrial marketplace. The baseline testing and optimization revealed that considerable energy savings can be realized by similar industrial facilities through conventional excess air tuning practices. 


\section{Background}

The Department of Energy, through the Industrial Technologies Program, has supported the development of a novel technology for control of industrial combustion systems. This work has been conducted by a team from the University of Missouri-Columbia (UMC), led by Professor Shahla Keyvan. Their Flame Image Analysis System (FIA) consists of a video camera mounted in a water-cooled housing. Advanced image analysis and artificial intelligence techniques are applied to analyze flame images. These diagnostics can be executed in real time using a notebook computer. The potential benefits attributable to this system include improved thermal efficiency, reduced $\mathrm{NO}_{\mathrm{x}}$ emissions, increased productivity, and improved product quality.

In October of 2006, the DOE awarded a contract to ENVIRON to verify and validate the FIA system through independent monitoring of a field trial. UMC arranged for these tests to be conducted at a commercial heat treating facility located in Missouri. This report documents the baseline operation of the heat treating furnace and then details the validation and verification experiment, procedures, and results.

\section{Heat Treating Furnace}

The field tests were performed at Missouri Forge, Inc., located in Doniphan, Missouri. This plant manufactures a wide variety of forged parts for the automotive, agricultural, oil and gas industries. The furnace selected by UMC for the validation and verification $(\mathrm{V} \& \mathrm{~V})$ testing is utilized for heat treating. This natural-gas-fired, batch furnace was manufactured by J. L. Becker (Figure 1). It is equipped with two 1.5 MM Btu/hr burners manufactured by Eclipse Corporation (Figure 2). These burners are mounted side-by-side and fire horizontally into a plenum located above the main furnace chamber. The combustion products flow over a separating baffle (the floor of the plenum) and then down into the main chamber where the parts are heated. The flue gas outlets are located at the main chamber's floor. The exiting gases flow up through five separate flues located within three sides of the furnace. The flue gases are collected by an overhead hood and exhaust fan.

The furnace fuel and air control system is illustrated schematically in Figure 3. The furnace is equipped with two unshielded thermocouples located in the main chamber. Total fuel flow rate to the furnace is modulated by an automatic controller. This unit adjusts firing rate based on an operator-selected furnace temperature set-point and the feedback signal received from one of the furnace thermocouples. A manual combustion air damper can be adjusted to set the overall combustion air flow rate. The air pressure downstream of this damper is supplied to an air-fuel ratio regulator, located immediately upstream of the fuel control valve. This regulator prevents the furnace excess air level from dropping below a pre-set value. For typical operations, the ratio regulator is only in control of excess air under high-fire conditions. Fuel and combustion air flow rates, exhaust gas composition, and flue gas exit temperature are not measured. 


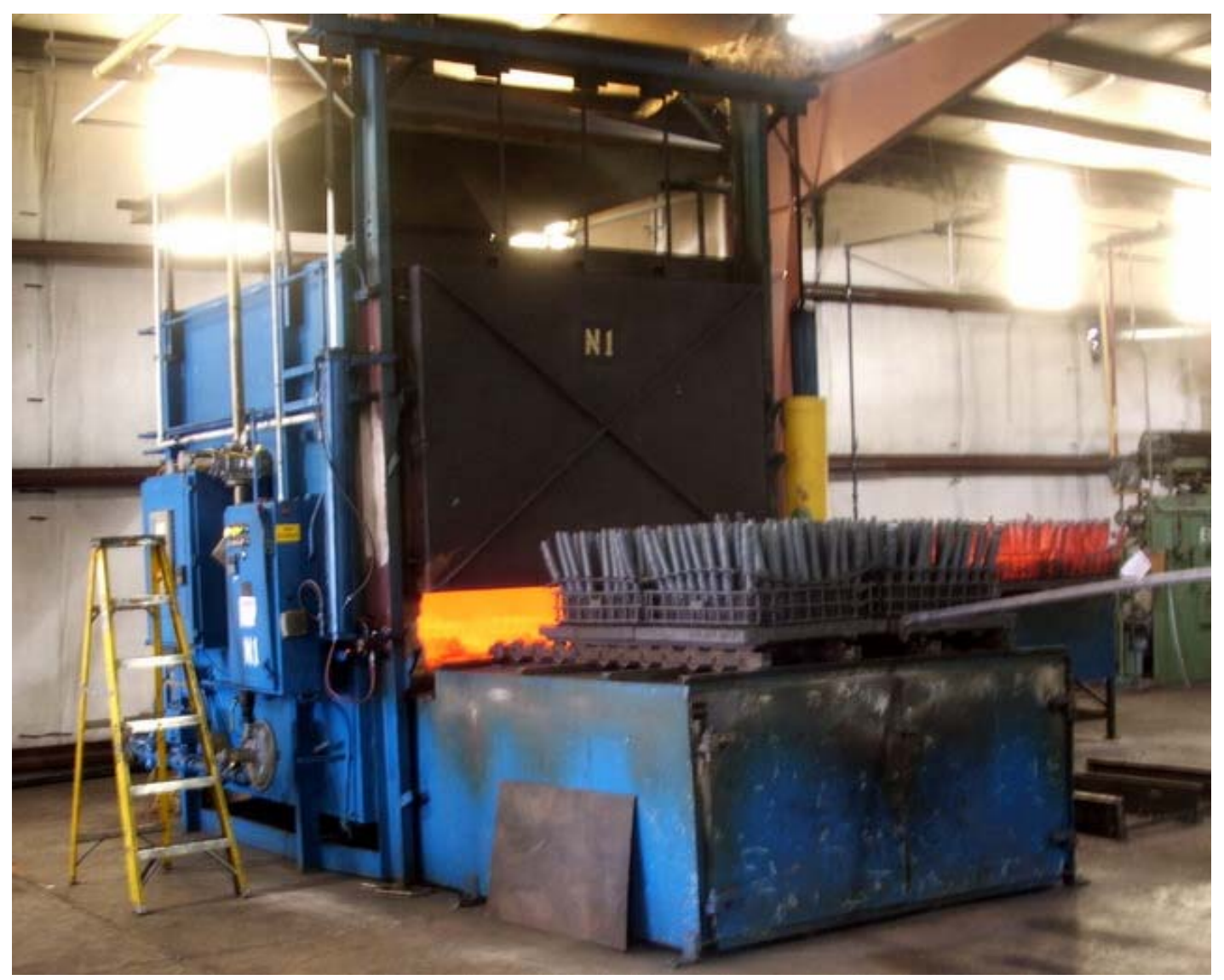

Figure 1. Test furnace at Missouri Forge. New load of transmission shafts about to be inserted into heat treating furnace.

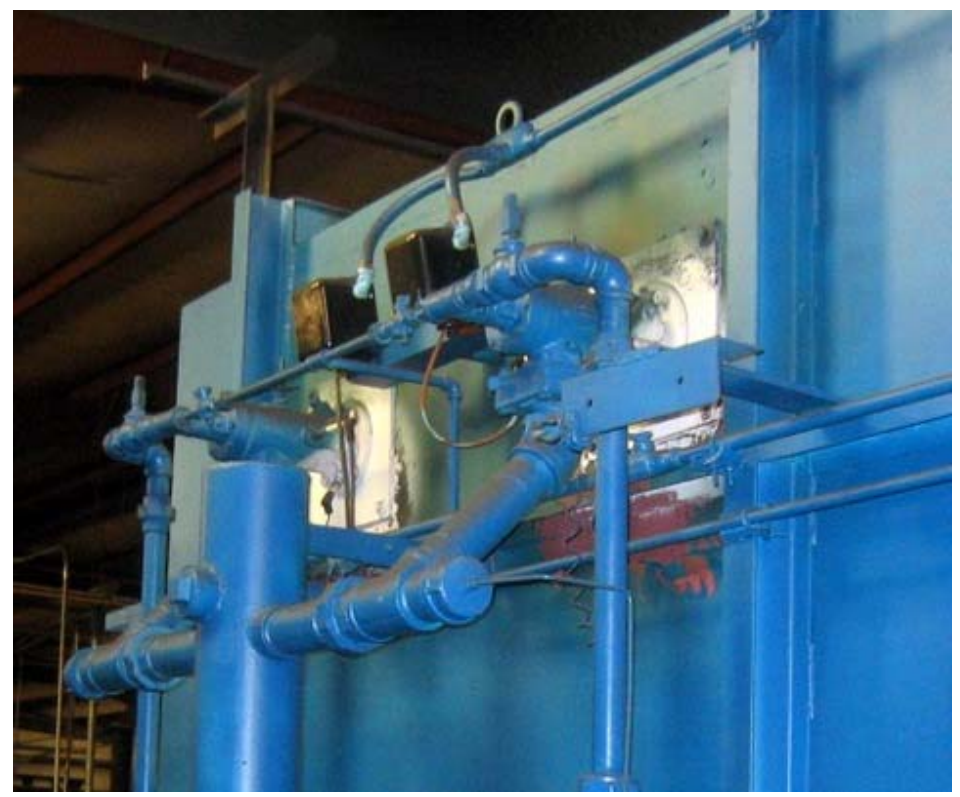

Figure 2. View of Eclipse burners installed in heat treating furnace. 


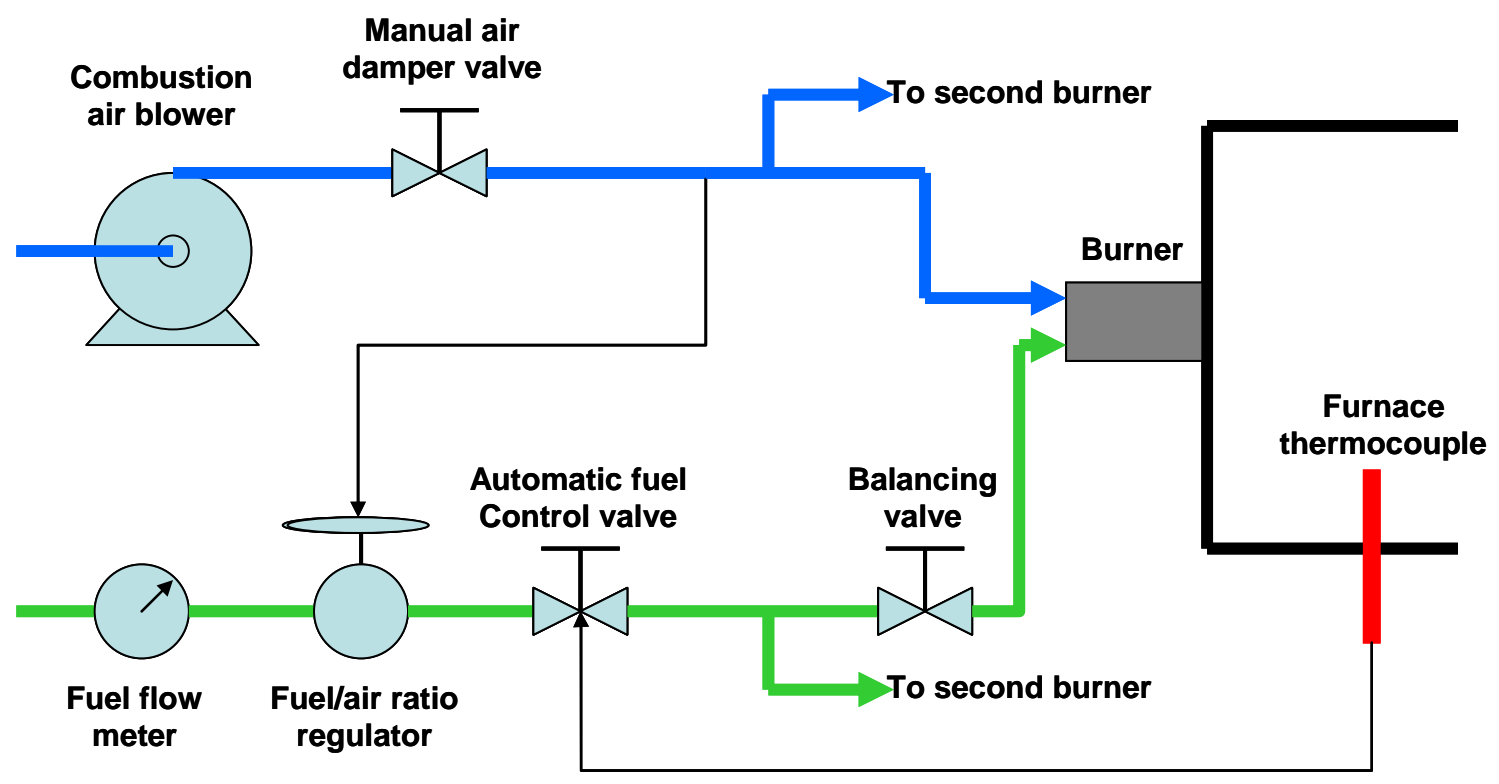

Figure 3. Schematic diagram of furnace fuel/air control system.

\section{Normal Production Operations}

The plant manufactures a wide variety of parts, each of which weighs anywhere from $0.25 \mathrm{lb}$ to $50 \mathrm{lb}$. Sizes and geometries vary, as do the applicable heat treating soaking times. Missouri Forge currently manufactures transmission shafts for an automotive application in significant volumes. This manufacturing process afforded the needed load consistency for the field evaluation of the FIA technology and we therefore conducted the field test during the heat treating of these transmission shafts.

A load consists of approximately 320 shafts and weighs approximately $3750 \mathrm{lb}$ (3000 pounds of shafts plus a 750 pound rack to hold the parts). A set of these shafts can be seen ready for loading into the furnace in Figure 1. The complete cycle time for each batch is 3 hours. This typically includes 1 hour for heat-up from hot idle conditions, 1 hour for temperature stabilization, and 1 hour for soaking at $1650^{\circ} \mathrm{F}$. The furnace normally operates on a 3-shift, 5-day work week. Thus, 8 batches of transmission shafts are treated in each 24 hour period.

\section{Instrumentation and Data Recording}

Additional instrumentation was procured and installed for the field test. Table 1 provides a list of the parameters recorded. 
Table 1. Parameters monitored and recorded during furnace tests.

\begin{tabular}{|l|l|}
\hline \multicolumn{1}{|c|}{ Parameter } & \multicolumn{1}{c|}{ Instrument } \\
\hline Fuel volume flow rate & $\begin{array}{l}\text { Dresser Roots Series B3 rotary } \\
\text { gas flow meter }\end{array}$ \\
\hline Fuel temperature & Thermocouple \\
\hline Fuel pressure & Pressure gauge \\
\hline Fuel composition & $\begin{array}{l}\text { Grab samples for off-line gas } \\
\text { chromatograph analysis }\end{array}$ \\
\hline Flue gas composition $\left(\mathrm{O}_{2}, \mathrm{CO}, \mathrm{NO}_{\mathrm{x}}\right)$ & $\begin{array}{l}\text { Testo Model 350 portable flue } \\
\text { gas analyzer }\end{array}$ \\
\hline Flue gas stack temperature & Thermocouple \\
\hline Furnace temperature & Thermocouples \\
\hline Ambient humidity & Sling psychrometer \\
\hline Ambient temperature & Thermocouple \\
\hline
\end{tabular}

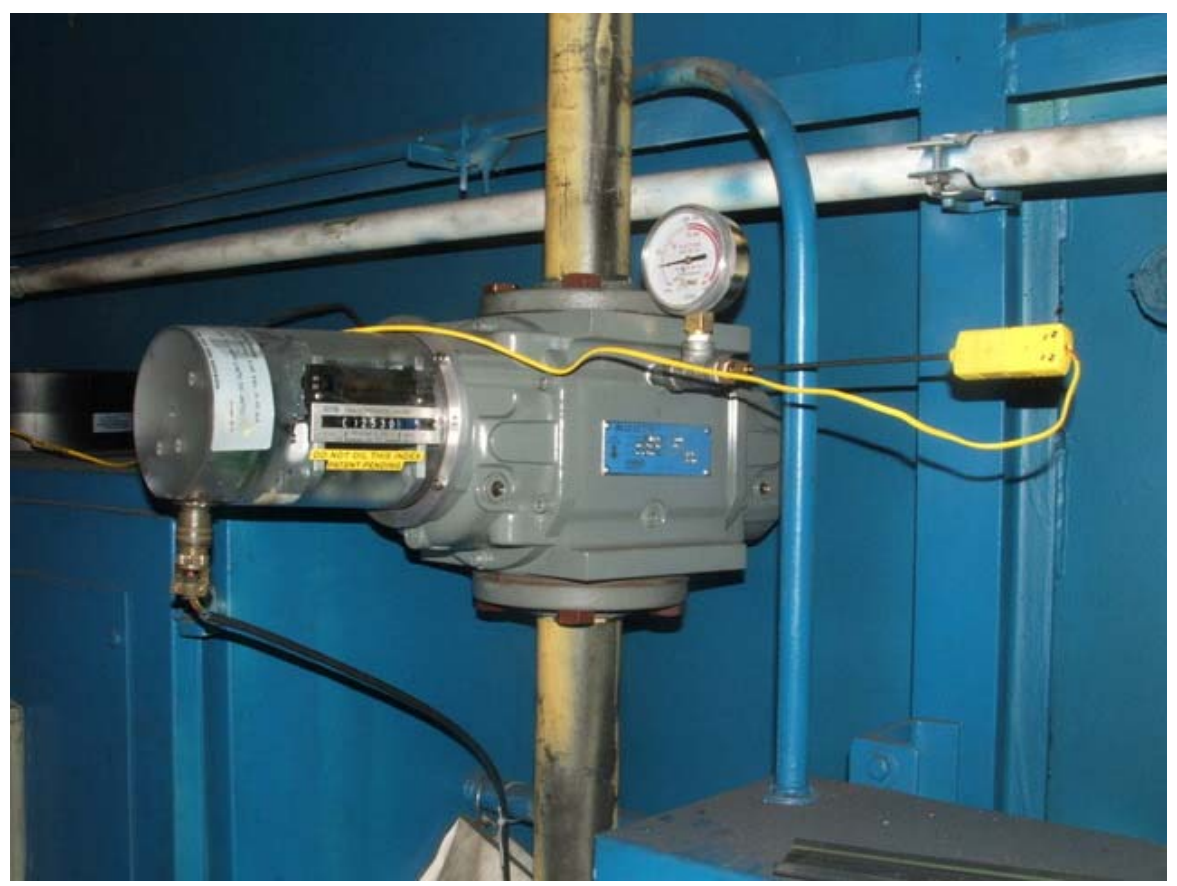

Figure 4. Fuel volume flow, pressure and temperature instrumentation installed on furnace gas 


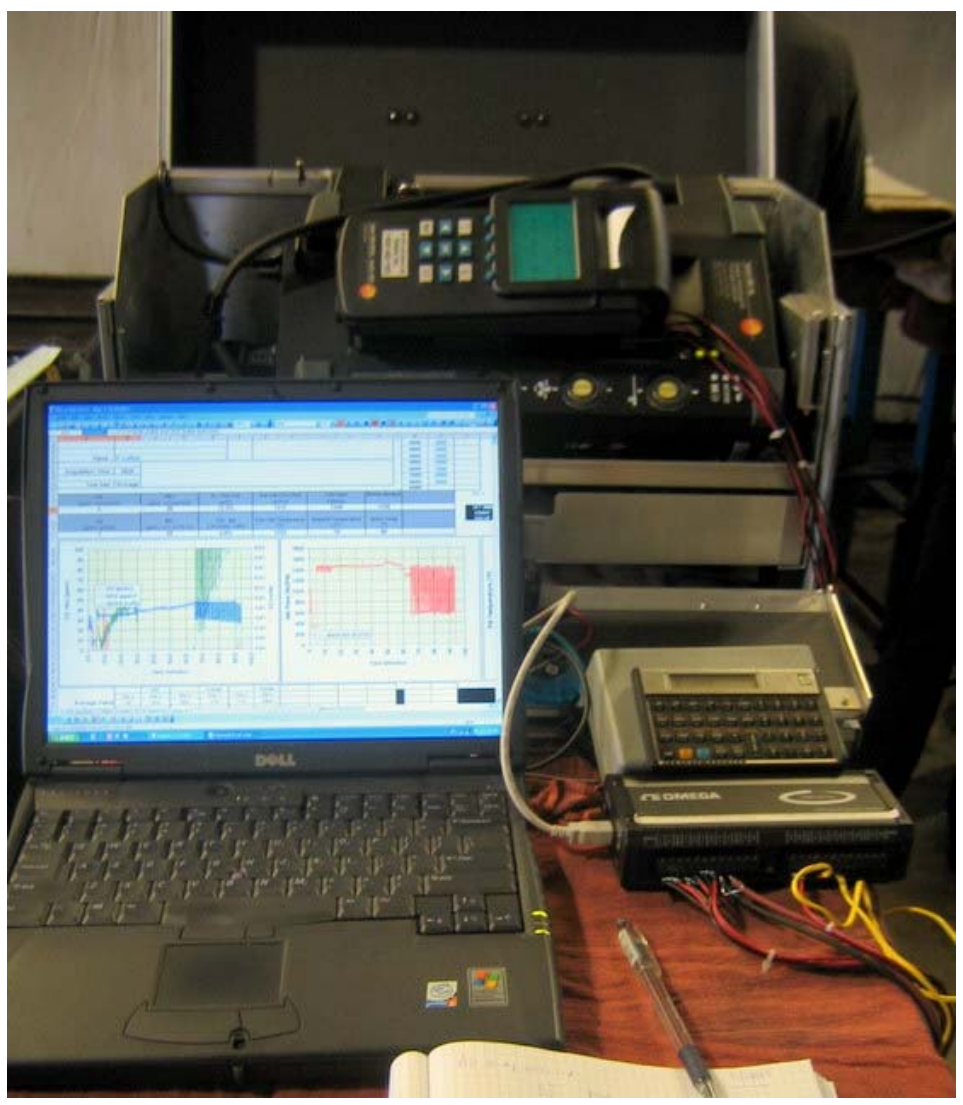

Figure 5. Flue gas analyzer and laptop-based data acquisition system during furnace test.

The fuel flow instrumentation installed on the furnace gas supply line is shown in Figure 4. The signals from the fuel flow meter, the flue gas analyzer and all thermocouples were routed to a portable data acquisition system. We used a USB-based data acquisition module (Omega OMB-DAQ-3000) and a laptop computer running Personal DAQView, a Microsoft Excel add-in (Figure 5). In addition, we tracked the normal heat treating quality parameters used by Missouri Forge.

\section{Test Activities}

The following Validation and Verification test sequence was proposed in our plan:

- $\quad$ Baseline Test to measure furnace performance as currently operated by Missouri Forge.

- Tuning of the furnace overall air-fuel ratio using a portable flue gas analyzer.

- Alternative Baseline Test to measure performance of the tuned furnace.

- Flame Image Analysis (FIA) diagnostics and furnace adjustments.

- Verification Test of fully optimized furnace performance. 
The testing at Missouri Forge was conducted during three separate periods.

March 2007

During the week of March 20, 2007, ENVIRON staff conducted baseline furnace tests. The objective of these tests was to install and check out all instrumentation and data acquisition equipment and then to conduct a series of tests monitoring furnace energy consumption during normal furnace operations while heat treating transmission shafts.

$\underline{\text { April } 2007}$

During the week of April 9, 2007, ENVIRON staff conducted additional baseline furnace tests. In addition, an alternative baseline was established by applying traditional energy efficiency optimization methods. This process involved reducing furnace excess air levels based on oxygen and carbon monoxide measurements obtained from a portable flue gas analyzer.

November 2007

During the week of November 26, 2007, ENVIRON staff and UMC staff conducted the Flame Image Analysis validation and verification tests. The Oak Ridge National Laboratory project manager was on site to observe key testing activities.

Table 2 presents a summary of the tests conducted during these three periods. Each test lasted for three hours, the normal heat treating time for a load of transmission shafts.

\section{Baseline Tests}

An initial set of six baseline runs were conducted in March 2007. These were followed by two more under the same furnace operating conditions in April 2007.

\subsection{Normal Furnace Operation}

A schematic illustrating the variation in furnace temperature during a typical cycle is shown in Figure 6. Once the load is inserted and the furnace is re-started, the burners operate at steady, high-fire conditions until the set-point temperature is reached $\left(1650^{\circ} \mathrm{F}\right.$ for the transmission shafts). This heat-up period takes slightly less than one hour. Once the set-point temperature has been reached, the furnace controller modulates the fuel flow to the burners to maintain the set-point temperature. The second hour is referred to as the stabilization period, and the third hour as the soak period. In general, as time progresses and the load reaches the target temperature, the average fuel flow rate decreases. But the controller is not capable of producing a steady decline in firing rate. Instead, the fuel flow cycles between low and medium firing rates with a period of just over one minute.

The fuel flow and flue gas oxygen concentration data for a complete baseline run (Run \#6, March 22, 2007) are shown in Figure 9. The flow rate is steady until approximately 45 minutes into the heating cycle, when it begins to fall off and start cycling. Figure 10 shows the variability in fuel flow and flue gas oxygen during the third hour soak period. For all baseline runs, the combustion air flow control damper was set at $40 \%$ open (Figure 7), the position originally selected and utilized by the facility. 
Table 2. Summary of furnace tests conducted.

\begin{tabular}{|c|c|c|l|}
\hline$\#$ & Date & $\begin{array}{c}\text { Approx. } \\
\text { Start } \\
\text { Time }\end{array}$ & \multicolumn{1}{|c|}{ Comments } \\
\hline 1 & $3 / 21 / 07$ & $7: 30$ & Baseline run, normal furnace operation, 40\% air damper position \\
\hline 2 & $3 / 21 / 07$ & $10: 30$ & Baseline run, normal furnace operation, 40\% air damper position \\
\hline 3 & $3 / 21 / 07$ & $13: 30$ & Baseline run, normal furnace operation, 40\% air damper position \\
\hline 4 & $3 / 22 / 07$ & $8: 30$ & Baseline run, normal furnace operation, 40\% air damper position \\
\hline 5 & $3 / 22 / 07$ & $11: 30$ & Baseline run, normal furnace operation, 40\% air damper position \\
\hline 6 & $3 / 22 / 07$ & $14: 30$ & Baseline run, normal furnace operation, 40\% air damper position \\
\hline 7 & $4 / 10 / 07$ & $11: 00$ & Baseline run, normal furnace operation, 40\% air damper position \\
\hline 8 & $4 / 10 / 07$ & $14: 00$ & Baseline run, normal furnace operation, 40\% air damper position \\
\hline 9 & $4 / 11 / 07$ & $8: 00$ & $\begin{array}{l}\text { Baseline run with manual control of fuel flow, 40\% air damper } \\
\text { position }\end{array}$ \\
\hline 10 & $4 / 11 / 07$ & $11: 00$ & $\begin{array}{l}\text { Alternative Baseline run: auto operation for hour 1, reduced air } \\
\text { damper settings and manual fuel control for hours 2 \& 3 }\end{array}$ \\
\hline 11 & $11 / 27 / 07$ & $10: 00$ & Baseline run with new furnace controller, 40\% air damper position. \\
\hline 12 & $11 / 27 / 07$ & $13: 00$ & $\begin{array}{l}\text { Optimized run with new furnace controller, 25\% air damper } \\
\text { position for first hour, 12.5\% air damper position for hours 2 \& 3 }\end{array}$ \\
\hline 13 & $11 / 28 / 07$ & $10: 00$ & Flame image analysis diagnostics \\
\hline 14 & $11 / 28 / 07$ & $13: 00$ & Flame image analysis diagnostics \\
\hline 15 & $11 / 28 / 07$ & $16: 00$ & Flame image analysis diagnostics \\
\hline 16 & $11 / 29 / 07$ & $10: 00$ & Flame image analysis diagnostics \\
\hline 17 & $11 / 29 / 07$ & $13: 00$ & Flame image analysis diagnostics \\
\hline
\end{tabular}

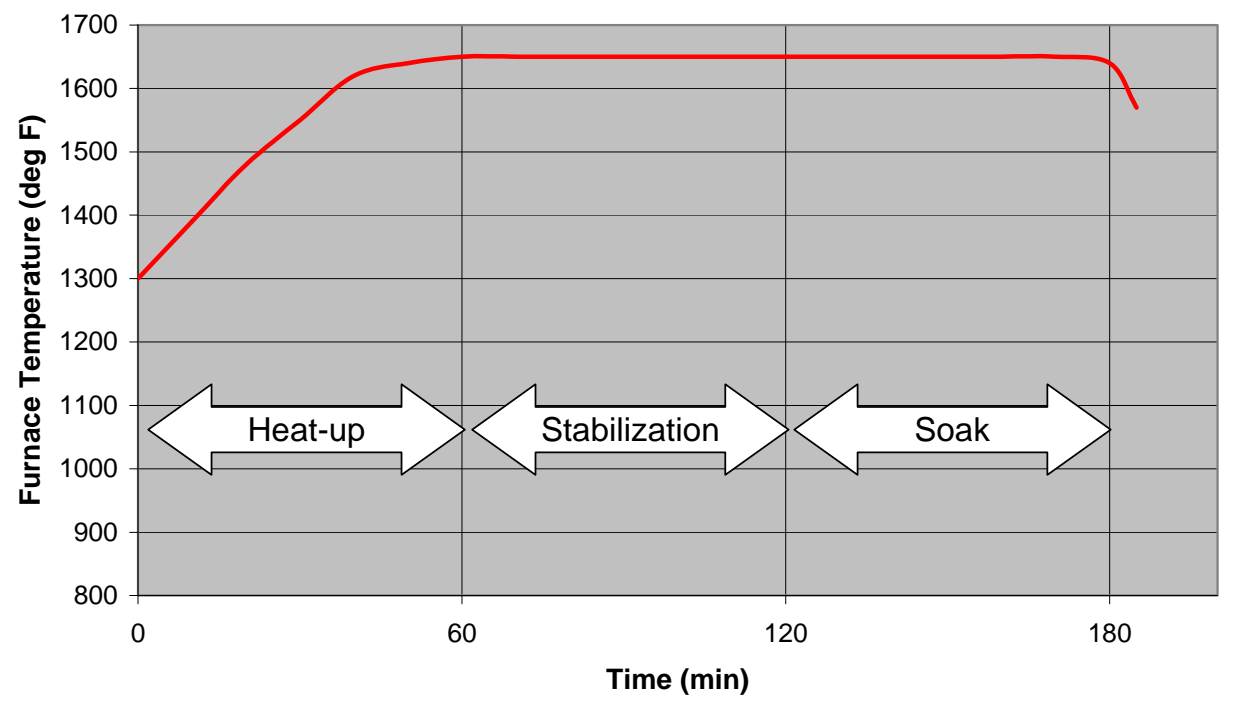

Figure 6. Schematic illustrating furnace temperature history during a normal heat treating operation and showing definition of heat-up, stabilization and soak phases of process. 


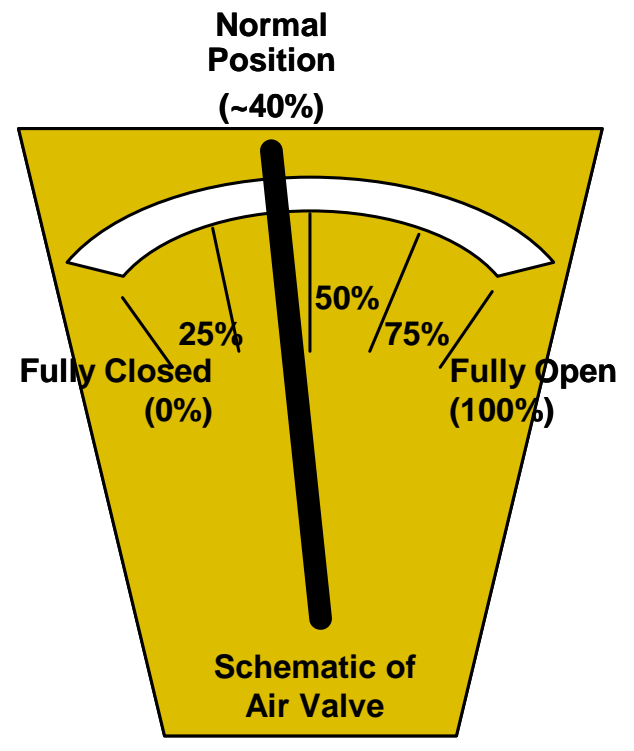

Figure 7. Schematic of combustion air flow control damper.

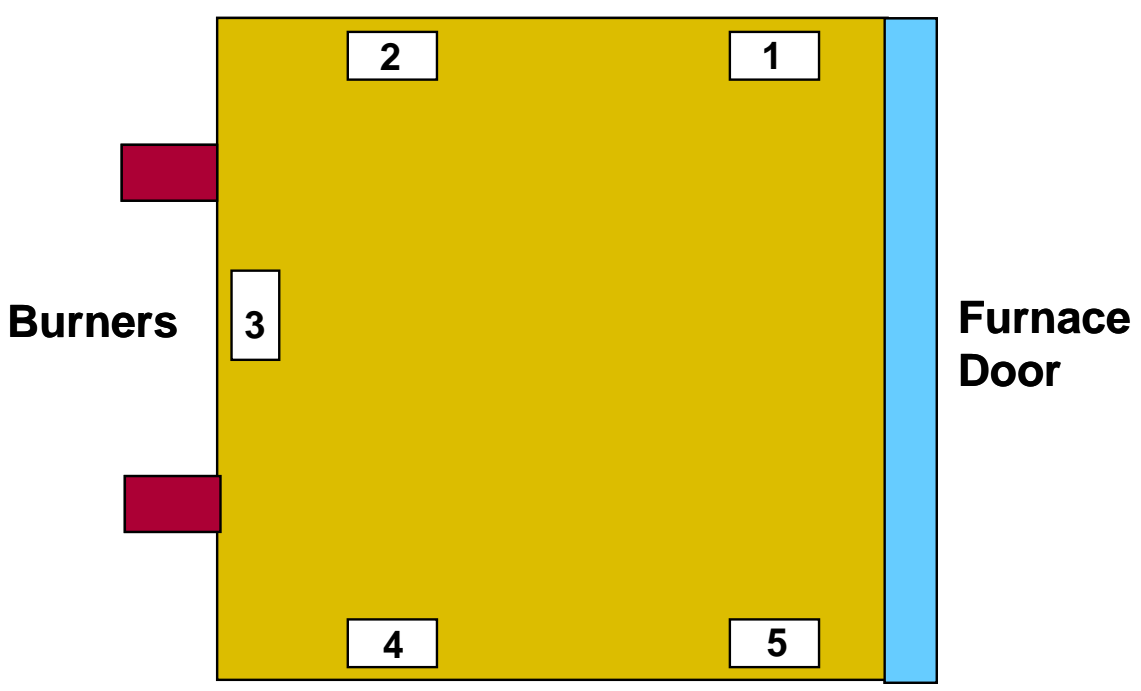

Figure 8. Schematic plan view of furnace showing location of the five flue passages. 


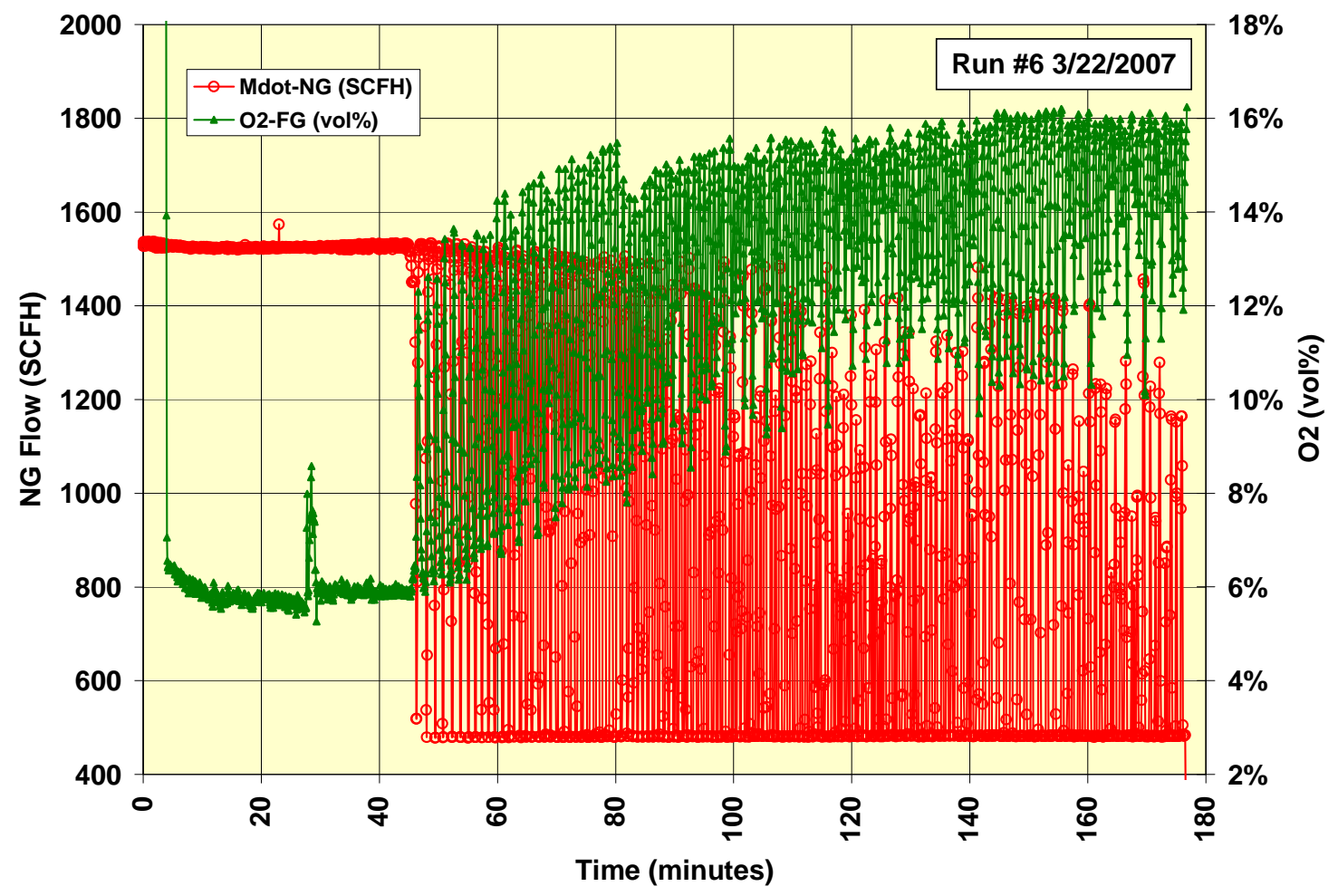

Figure 9. Fuel flow rate and flue \#4 oxygen concentration data for baseline run \#6.

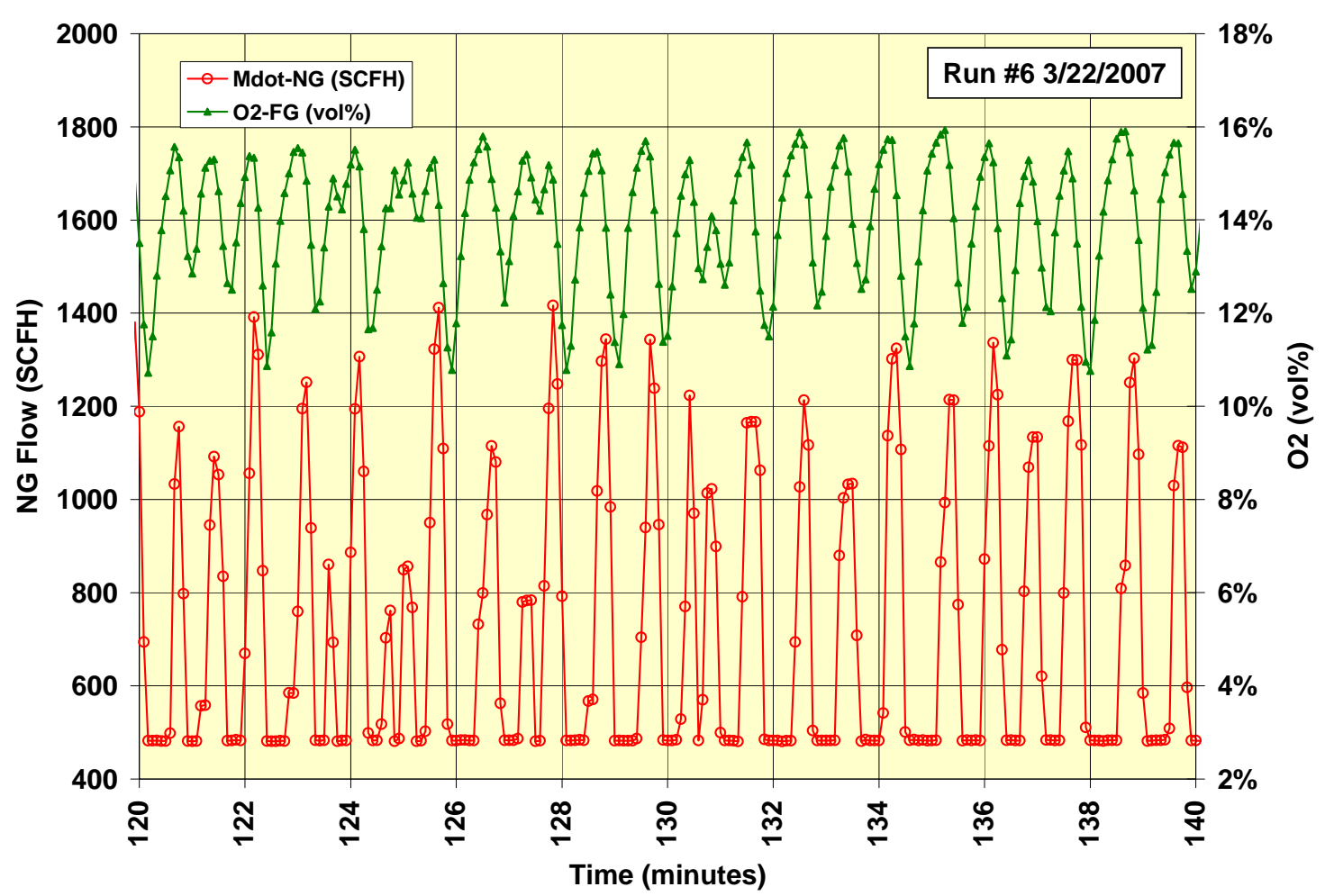

Figure 10. Fuel flow rate and flue \#4 oxygen concentration data for baseline run \#6, showing flowrate and concentration fluctuations during the soak phase of the process. 
The furnace is equipped with five separate flue passages. These originate below the furnace floor and pass up through the furnace walls on three sides of the furnace (schematic provided in Figure 8). During the first five baseline tests, our gas sampling protocol was to insert the flue gas probe into each flue until steady readings were obtained. The five readings were then averaged to give an overall flue gas composition.

Considerable variability in flue gas composition was noted between the five flues. Illustrative data for flue gas sampling at high-fire (i.e. steady fuel flow) conditions are provided in Table 3 below.

Table 3. Illustrative flue gas data for all five flue passages at high fire condition.

\begin{tabular}{|l|r|r|r|r|r|r|}
\hline & Flue 1 & Flue 2 & Flue 3 & Flue 4 & Flue 5 & Average \\
\hline $\mathrm{O}_{2}$ & $7.1 \%$ & $4.3 \%$ & $7.6 \%$ & $2.2 \%$ & $3.0 \%$ & $4.8 \%$ \\
$\mathrm{CO}(\mathrm{ppmv})$ & 0 & 20 & 397 & 0 & 0 & 83 \\
$\mathrm{NO}(\mathrm{ppmv})$ & 27 & 33 & 21 & 34 & 33 & 30 \\
$\mathrm{~T} \mathrm{FG} \mathrm{(deg} \mathrm{F)}$ & 1,170 & 1,216 & 1,052 & 1,255 & 1,306 & 1,200 \\
$\mathrm{CO}$ (ppmv-air free) & 0 & 26 & 625 & 0 & 0 & 130 \\
$\mathrm{NO}(\mathrm{ppmv}-3 \% \mathrm{O} 2)$ & 35 & 36 & 28 & 33 & 33 & 33 \\
\hline
\end{tabular}

Run \#1 3/21/3007 Hour 1

In the example shown, the measured flue gas oxygen concentration varied between $2.2 \%$ and $7.7 \%$ among the different flues. In addition, flue 3 consistently showed the presence of carbon monoxide, which was essentially absent in the other four flues. The reason for having elevated CO in only one flue was never fully established.

\subsection{Baseline Energy Consumption}

Baseline energy consumption data is shown in Table 5, below. Fuel volume flow data was converted to energy flow using the measured fuel heating value. Natural gas samples were taken during Runs 1, 3, 4, 5, 7, 10 and 11.. These gas samples were analyzed after the test period by EMPACT Analytical Systems. The results of the gas analyses are presented in Table 4. The gas composition was remarkably consistent over the entire test period, with a very small change in heating value. 
Table 4. Compositions and heating values for gas samples

\begin{tabular}{|l|r|r|r|r|r|r|r|}
\hline Sample Details & & & & & & \\
Date & $3 / 21 / 2007$ & $3 / 21 / 2007$ & $3 / 22 / 2007$ & $3 / 22 / 2007$ & $4 / 10 / 2007$ & $4 / 11 / 2007$ & $11 / 27 / 2007$ \\
Time & $9: 40$ & $14: 15$ & $9: 45$ & $13: 35$ & $13: 35$ & $11: 20$ & $11: 10$ \\
Run & 1 & 3 & 4 & 5 & 7 & 10 & 11 \\
\hline Components (mol\%) & & & & & & \\
Helium & 0.03 & 0.03 & 0.03 & 0.03 & 0.03 & 0.03 & 0.04 \\
Hydrogen & 0.01 & 0.00 & 0.00 & 0.00 & 0.00 & 0.00 & 0.00 \\
Oxygen/Argon & 0.00 & 0.02 & 0.00 & 0.00 & 0.02 & 0.01 & 0.02 \\
Nitrogen & 0.83 & 0.96 & 0.96 & 0.97 & 1.07 & 1.05 & 0.99 \\
Carbon Dioxide & 1.07 & 1.05 & 1.03 & 0.99 & 1.11 & 1.08 & 1.19 \\
Methane & 94.50 & 94.58 & 94.48 & 94.60 & 94.26 & 94.54 & 94.41 \\
Ethane & 2.80 & 2.61 & 2.71 & 2.65 & 2.67 & 2.56 & 2.67 \\
Propane & 0.48 & 0.47 & 0.49 & 0.47 & 0.54 & 0.46 & 0.45 \\
Isobutane & 0.07 & 0.08 & 0.08 & 0.08 & 0.09 & 0.09 & 0.07 \\
N-Butane & 0.10 & 0.10 & 0.11 & 0.10 & 0.12 & 0.10 & 0.09 \\
Isopentane & 0.04 & 0.04 & 0.04 & 0.04 & 0.04 & 0.04 & 0.03 \\
N-Pentane & 0.03 & 0.03 & 0.03 & 0.03 & 0.02 & 0.02 & 0.02 \\
Hexanes+ & 0.04 & 0.03 & 0.04 & 0.04 & 0.02 & 0.02 & 0.02 \\
\hline HHV (BTU/scf) & 1031.1 & 1028.1 & 1030.2 & 1029.5 & 1028.10 & 1025.90 & 1024.90 \\
\hline
\end{tabular}

Table 5. Baseline energy consumption data.

\begin{tabular}{|c|c|c|c|c|c|}
\hline & & \multicolumn{4}{|c|}{} \\
\hline Date & & \multicolumn{4}{|c|}{ Energy Input (MMBTU) } \\
\hline $3 / 21 / 2007$ & 1 & 1.541 & 0.966 & 0.755 & 3.262 \\
\hline $3 / 21 / 2007$ & 2 & 1.544 & 0.927 & 0.713 & 3.183 \\
\hline $3 / 21 / 2007$ & 3 & 1.538 & 0.914 & 0.748 & 3.200 \\
\hline $3 / 22 / 2007$ & 4 & 1.563 & 0.928 & 0.744 & 3.234 \\
\hline $3 / 22 / 2007$ & 5 & 1.573 & 0.981 & 0.757 & 3.311 \\
\hline $3 / 22 / 2007$ & 6 & 1.507 & 0.919 & 0.738 & 3.163 \\
\hline $4 / 10 / 2007$ & 7 & 1.549 & 1.014 & 0.806 & 3.369 \\
\hline $4 / 10 / 2007$ & 8 & 1.602 & 0.990 & 0.796 & 3.389 \\
\hline & & & & & \\
\hline Baseline Averages & Average & 1.552 & 0.955 & 0.757 & 3.264 \\
\hline & $\sigma$ & 0.028 & 0.038 & 0.031 & 0.085 \\
\hline & olaverage & $1.8 \%$ & $4.0 \%$ & $4.0 \%$ & $2.6 \%$ \\
\hline
\end{tabular}


Table 6. Flue gas composition data for baseline tests.

\begin{tabular}{|c|c|c|c|c|c|c|c|c|c|c|}
\hline \multirow[b]{2}{*}{ Date } & \multirow[b]{2}{*}{ Run \# } & \multicolumn{3}{|c|}{ Flue Gas Oxygen (vol\%) } & \multicolumn{3}{|c|}{$\begin{array}{c}\text { Flue Gas Carbon Monoxide } \\
\text { (ppmv, air-free) }\end{array}$} & \multicolumn{3}{|c|}{$\begin{array}{l}\text { Flue Gas } \mathrm{NO}_{x}(\mathrm{ppmv}, \\
\left.\text { corrected to } 3 \text { vol\% } \mathrm{O}_{2}\right)\end{array}$} \\
\hline & & Hour 1 & Hour 2 & Hour 3 & Hour 1 & Hour 2 & Hour 3 & Hour 1 & Hour 2 & Hour 3 \\
\hline $3 / 21 / 2007$ & 1 & $4.8 \%$ & $12.1 \%$ & $13.8 \%$ & 108 & 206 & 293 & 33 & $\overline{51}$ & 48 \\
\hline $3 / 21 / 2007$ & 2 & $5.3 \%$ & $13.8 \%$ & $14.2 \%$ & 147 & 252 & 270 & 34 & 46 & 47 \\
\hline $3 / 21 / 2007$ & 3 & $5.0 \%$ & $12.0 \%$ & $13.2 \%$ & 122 & 204 & 247 & 33 & 48 & 48 \\
\hline $3 / 22 / 2007$ & 4 & $5.5 \%$ & $12.5 \%$ & $13.7 \%$ & 123 & 262 & 326 & 35 & 49 & 50 \\
\hline $3 / 22 / 2007$ & 5 & $4.9 \%$ & $13.2 \%$ & $13.8 \%$ & 110 & 208 & 130 & 34 & 46 & 49 \\
\hline Baseline Averages & Average & $5.1 \%$ & $12.7 \%$ & $13.7 \%$ & 122 & 226 & 253 & 34 & 48 & 48 \\
\hline & $\sigma$ & $0.3 \%$ & $0.8 \%$ & $0.3 \%$ & 15 & 28 & 75 & 1 & 2 & 1 \\
\hline & б/average & $5.3 \%$ & $6.0 \%$ & $2.5 \%$ & $12.7 \%$ & $12.5 \%$ & $29.6 \%$ & $2.3 \%$ & $4.2 \%$ & $2.0 \%$ \\
\hline & & & & & & & & & & \\
\hline
\end{tabular}

Table 5 shows the energy consumption for each hour of operation during the test. The eight runs showed a minimum energy consumption of 3.183 MMBTU and a maximum of 3.389 MMBTU. The average energy consumption was 3.264 MMBTU with a standard deviation of 0.085 MMBTU or $2.6 \%$.

Average flue gas composition data for the baseline runs, again broken down by hour of operation, are shown in Table 6. For the first hour of operation (burners at high fire, fuel flow steady), the flue gas average oxygen level was around 5\% (approximately 25\% excess air). This is a reasonable excess air level, though fuel savings could be realized by reducing excess air to around 15\%, or approximately 3\% oxygen. However, during the stabilization and soak phases (hours 2 and 3, burners cycling, air flow fixed), the average oxygen concentration was between $13 \%$ and $14 \%$. These oxygen concentrations indicate that the excess air level was about 140\%. Thus, significant reductions in excess air levels during the second and third hours are possible and could yield significant energy savings.

Before such savings can be captured, two furnace operational issues should be addressed. First, lowering excess air during the first hour of operation will increase temperatures in the furnace's upper chamber. The impact of higher baffle temperatures on the life of that component should be evaluated. Second, significant reductions in excess air during the second and third hour would lower flue gas velocities in the lower chamber. This change could affect product temperature uniformity and, therefore, product quality.

\subsection{Excess Air Reductions for Improved Efficiency (Alternative Baseline)}

Normal furnace operation is clearly not optimal with respect to thermal efficiency. Excess air levels are very high and therefore stack losses are higher than necessary. Accordingly, two tests were conducted in April, 2007 to assess the energy consumption benefits that could be achieved using standard flue gas analysis equipment. 
In the first of these tests, Run \#9 conducted on April 11 manual control of fuel flow was employed to reduce flow rate cycling. Furnace operation was modified as follows:

- First hour: normal operation as in baseline tests.

- Second and third hours: fuel valve controlled manually (to avoid burner cycling); air damper left in normal baseline position (40\%).

In the second of these tests, Run \#10, also conducted on April 11, furnace operation was modified as follows:

- First hour: normal operation as in baseline tests. We elected not to reduce excess air due to concerns regarding the baffle temperature.

- Second and third hours: fuel valve controlled manually (to avoid burner cycling); air valve controlled manually to reduce overall excess air level.

Fuel flow data for these manually controlled runs are shown in Figure 11. The energy consumption data for these tests is provided in Figure 12, where it is compared to the average and range of baseline energy consumption from Runs 1 through 8. Run 9 consumption was 3.245 MMBTU, very close to the baseline average of 3.264 MMBTU. Eliminating the burner cycling without reducing the excess air levels therefore produced no benefit. However, energy consumption for Run 10 was 2.757 MMBTU, a 15\% reduction from the average baseline value, showing the benefit of excess air control.

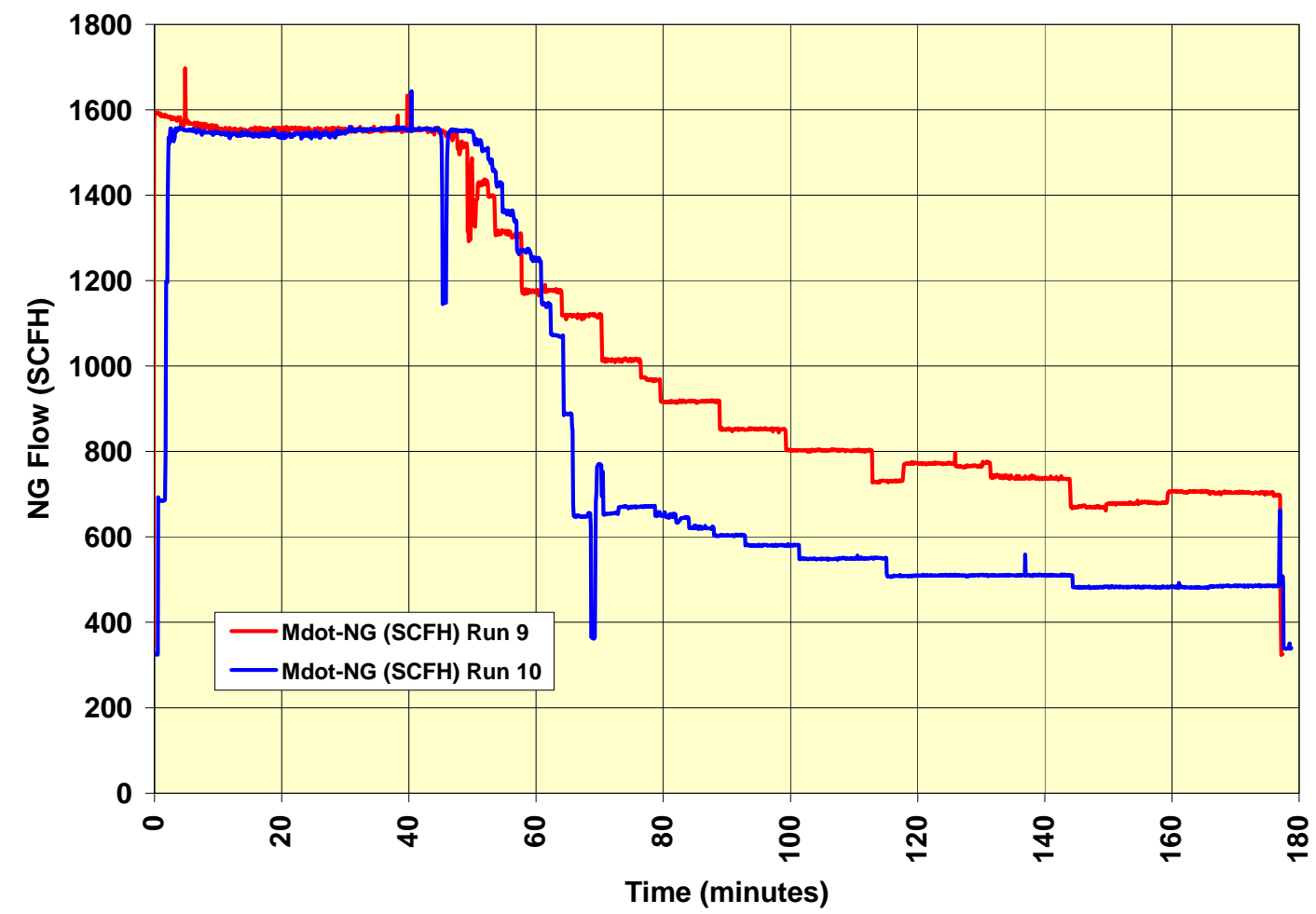

Figure11. Fuel flow data for manually controlled runs. 


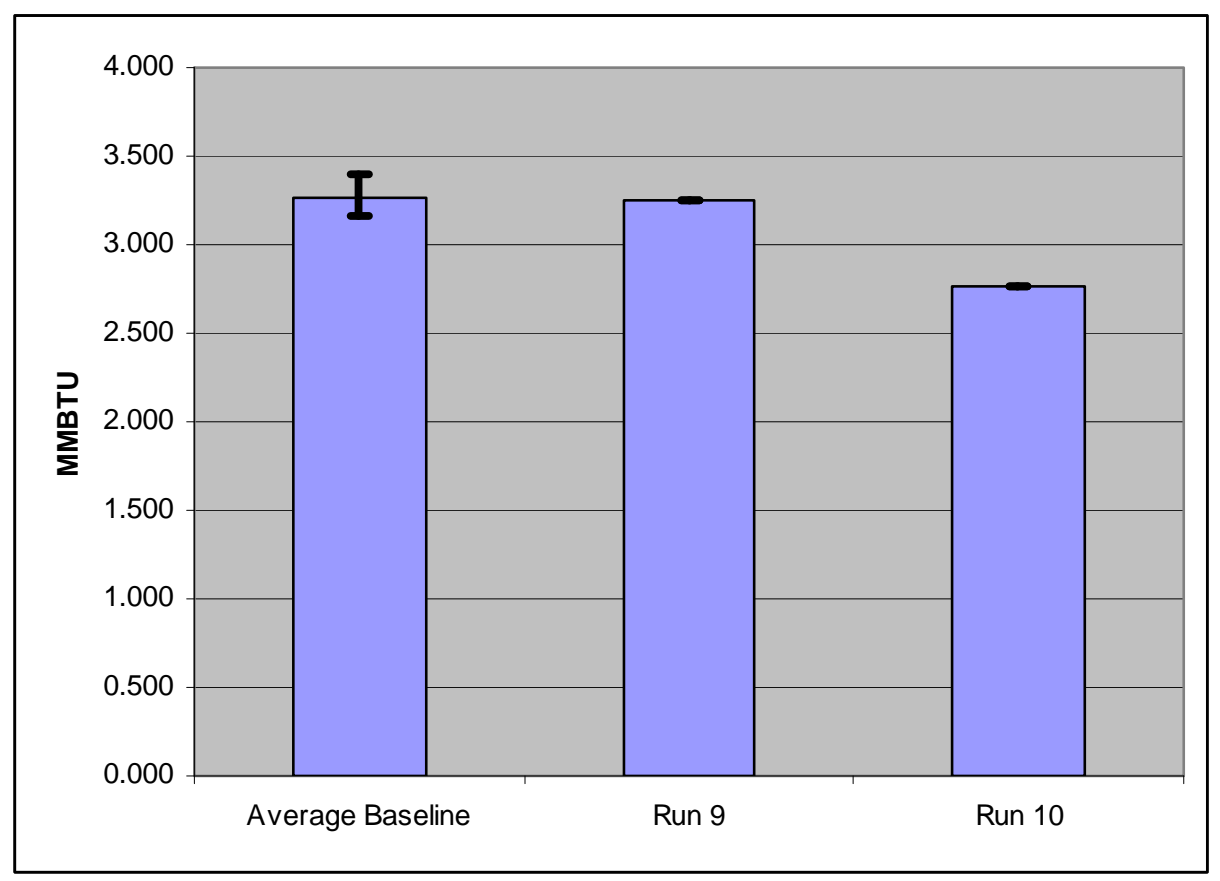

Figure 12. Energy consumption data for manually-controlled tests.

Excess air reductions beyond those achieved in Run 10 could further reduce energy consumption. However attempts to operate during the soak period with even lower excess air failed, as the ratio regulator turned the fuel flow off. Thus, we believe a $15 \%$ reduction in energy consumption relative to the baseline represents a practical limit which can be achieved with the existing equipment. Product quality achieved in run 10 was satisfactory. However, a small, relatively cool region near the furnace door was visually noted when the batch was removed.

\subsection{New Furnace Controller}

The furnace controller was replaced during September, 2007, before the FIA tests had been conducted. We therefore conducted several additional baseline energy consumption tests with the new controller in place in order to verify that the previous baseline data was still valid.

Fuel flow data for Run \#11 on November 27, 2007 are shown in Figures 13 and 14, where they are compared to that for an earlier baseline run at the same air damper setting, Run \#7. The furnace behavior was very similar to that observed during the March and April testing, with periodic burner cycling and very high excess air levels during the stabilization and soak periods. As can be seen in Figures 13 and 14, the new controller has not improved the control of burner firing rate during the soak periods. 


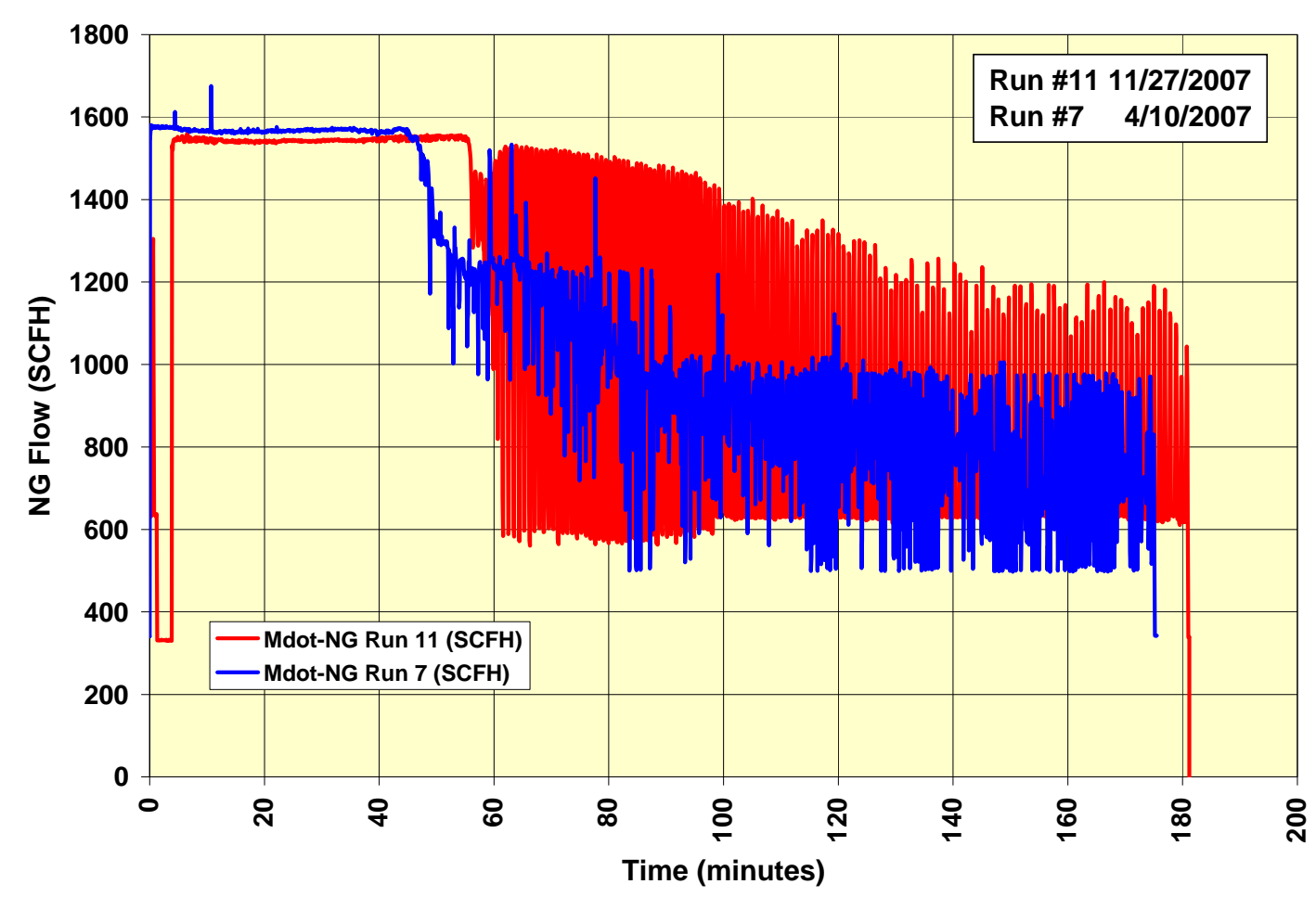

Figure 13. Fuel flow data for baseline test with new (Run \#11) and old (Run \#7) furnace controllers.

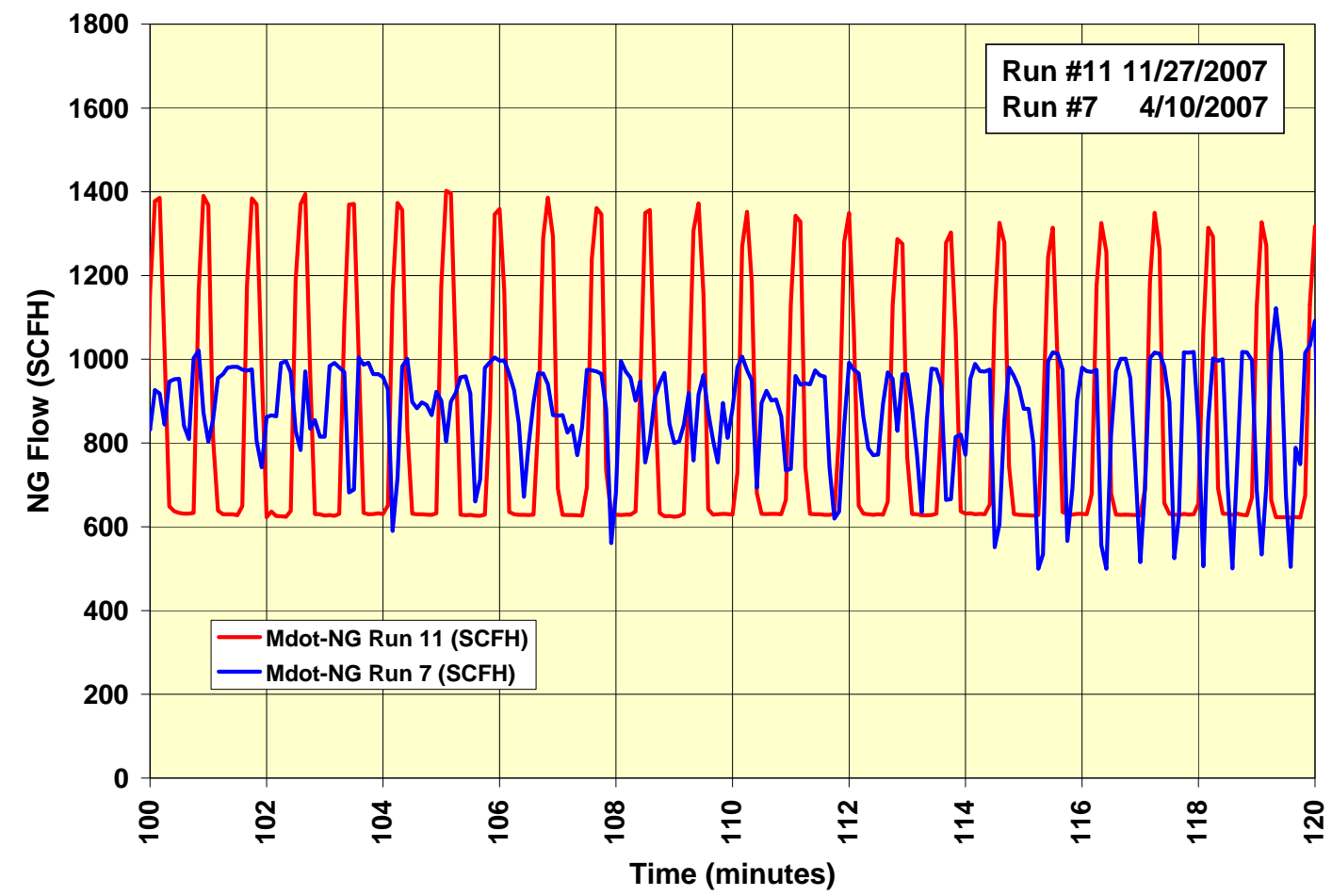

Figure 14. Blowup of data from Figure 13, showing burner cycling during soak period. 
Run \#11 on November 27, 2007, was conducted with the air damper at the $40 \%$ position and was thus a repeat of Runs \#1 through \#8.. Energy consumption was 3.265 MMBTU, identical to the average value for Runs \#1 through \#8. We therefore concluded that the new controller had not significantly changed the baseline energy consumption per load, even though the period and extent of burner cycling during the soak period was quite different with the new controller.

\section{Flame Image Analysis Tests}

Staff from UMC visited Missouri Forge for the FIA verification testing on November 28 and 29, 2007. Several other visits had been made to conduct test work in the furnace over the preceding 18 months or so. The test plan prepared by UMC staff (provided in the Appendix) called for the following activities on the first day:

- First Run: Conduct flame image analyses at two points in time within the $180 \mathrm{~min}$ heat treating cycle (40 and 160 minutes). These points in time should correspond to the highest and lowest burner firing rates, under normal operation. For each analysis, the air damper will be adjusted to 5 different positions. Each position will be held for about 5 seconds. These results will be evaluated to define the optimum air damper position(s) for the next two batches.

- Second Run: Operate the furnace using the recommended air damper settings from the First Run analyses. Monitor fuel consumption and flue gas composition.

- Third Run: Same as Second Run. Duplicate test for assessment of batch-to-batch variability.

\subsection{Heat-up Period Optimization}

The camera, in a water-cooled housing, was installed into a viewport in the furnace (Figure 15) and Run \#13 was commenced on November 28, 2007. After 43 minutes of heating, air damper adjustments were initiated. As stated in the UMC test plan, it was anticipated that the FIA system would "show and select the optimum air flow". UMC personnel observed a computed parameter displayed in real time on their computer system. The nature of the parameter and its derivation were not made available to us. We were permitted to observe the parameter plotted on the computer screen and were informed by UMC staff that they were looking for the parameter to pass through a maximum as the furnace performance was adjusted. The optimum adjustment for efficient furnace operation would then correspond to the maximum value of the parameter.

The adjustments started with the damper being moved from the $25 \%$ open setting to the $40 \%$ open setting. The damper was then progressively closed in five steps over a 16 minute period. It was observed during this process that as the air damper was opened the fuel flow increased, and vice versa (Figure 16). Consequently, the excess air level in the furnace was only altered in a relatively narrow range. 


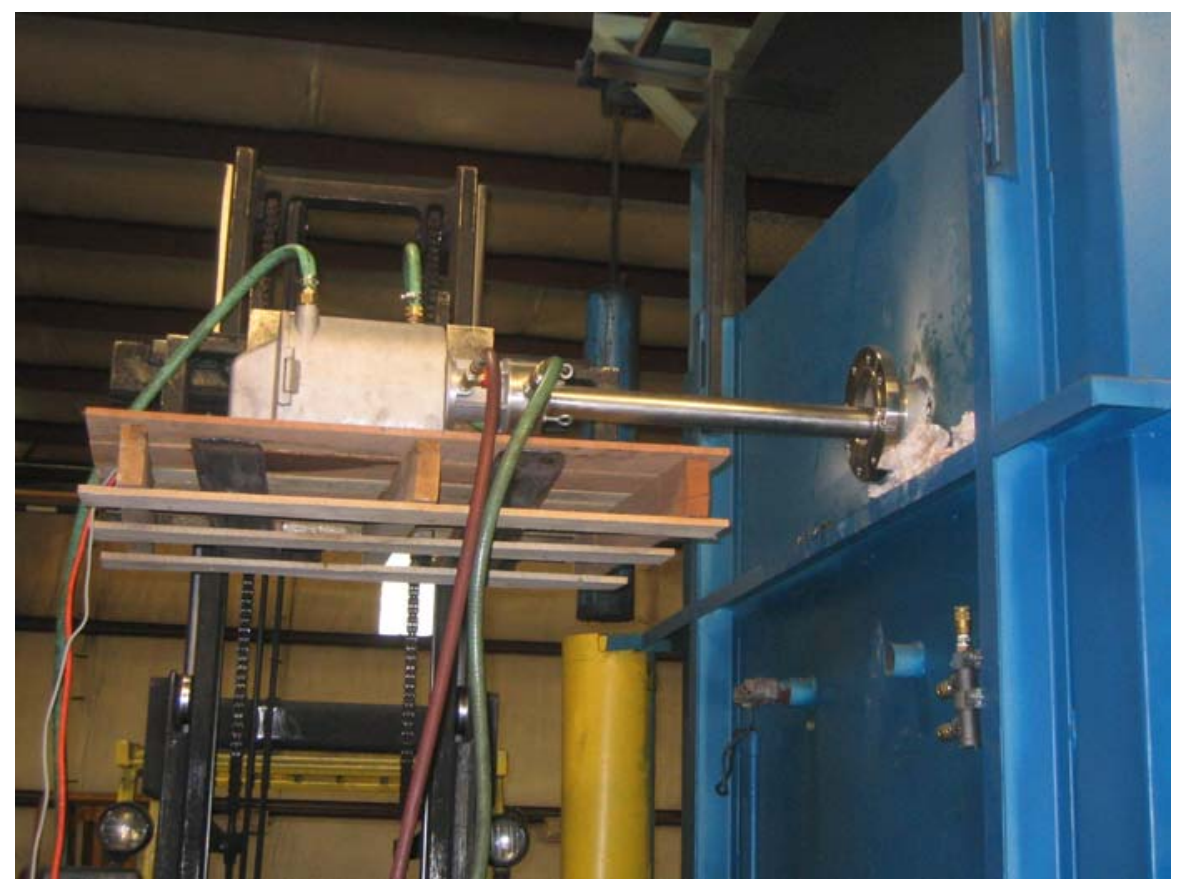

Figure 15. Camera in water cooled probe installed in furnace.

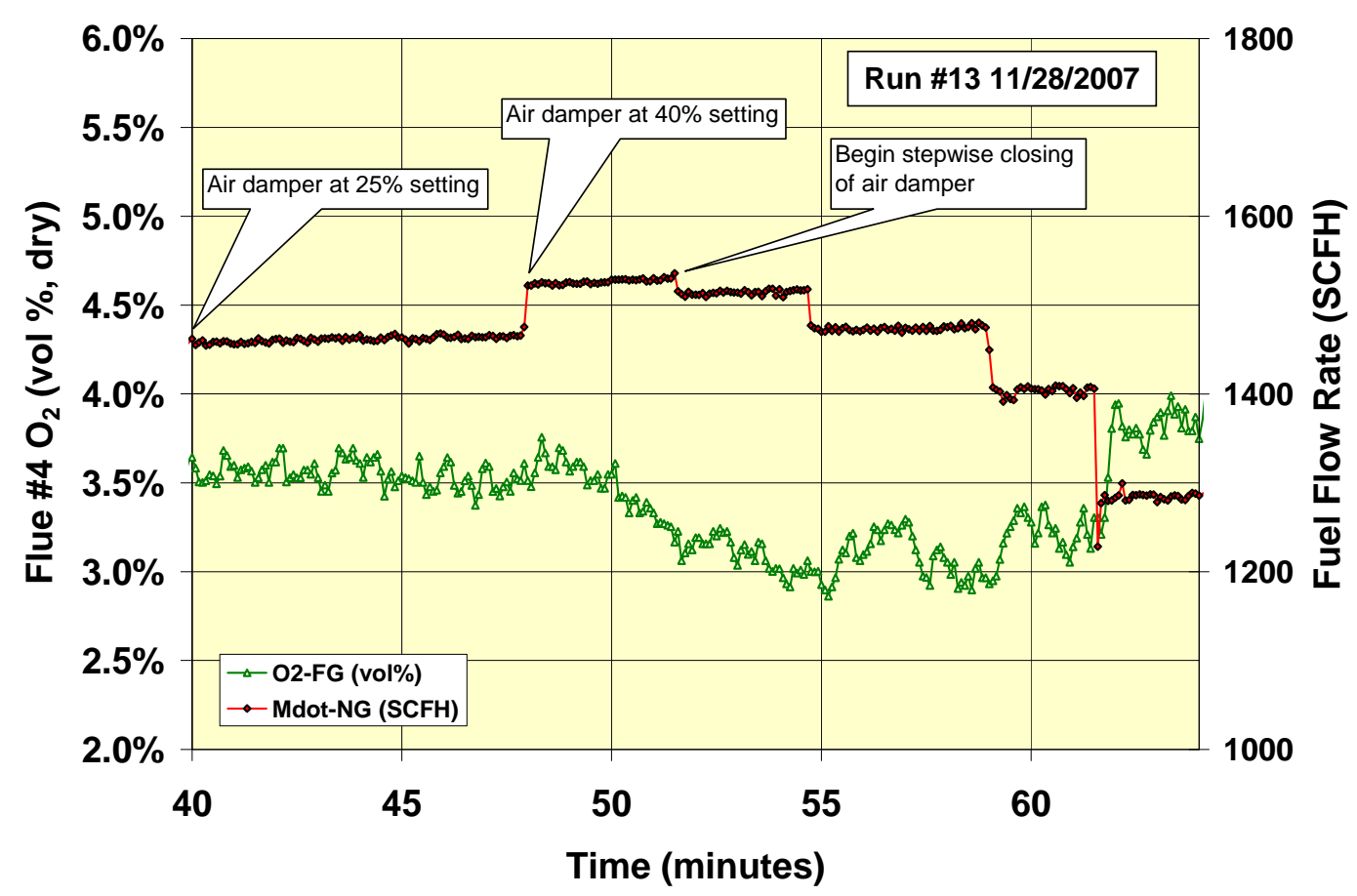

Figure 16. Fuel flow and exhaust oxygen data for FIA testing during Run \#13 - fuel flow decreases as air damper is closed and vice versa. 
Observation of the UMC computer screen indicated that the parameter of interest increased monotonically during this test period and that a maximum value was not obtained.

\subsection{Soak Period Optimization}

Additional FIA testing was conducted during the soak periods of Run \#13, when the burner firing rate was cycling. Under these conditions, the FIA parameter also cycled. The value of the parameter appeared to rise and fall with burner firing rate. UMC staff indicated that optimum performance would be attained when the amplitude of the parameter's cycle reached a minimum. According to the test plan the FIA system would "show and select the optimum air flow" during this soak period. However, over the range of air damper position evaluated by UMC, the FIA system was again unable to identify an optimum condition. Regarding this outcome, it should be noted that the alternative baseline testing revealed that extremely low air damper settings are needed to fully optimize excess air levels at low firing rates.

\subsection{Heat-up Period Optimization - Second Attempt}

Given the inability of the FIA system to identify optimum conditions during the first batch, the test sequence as planned could not be followed. Instead, more opportunities were provided to the UMC team to demonstrate that their instrumentation could clearly identify optimum air damper positions.

During the next furnace batch (Run \#14), an additional set of FIA tests was conducted during high fire conditions. Once again, the parameter of interest was observed to increase monotonically with time, and no maximum was observed. During this test too, the furnace excess air level varied only within a narrow range.

\subsection{Burner Balancing}

During the soak period of Run \#14, burner balancing tests using the FIA system were conducted. The objective of balancing in a multi-burner furnace is to achieve uniform airfuel ratios for the supplies delivered to each burner. Once balancing is accomplished, the overall furnace excess air level can be reduced to a level lower than that possible with unbalanced burners. This extra reduction, with an associated efficiency gain, is possible since optimum carbon monoxide levels are achieved at a lower excess air level with properly balanced burners.

The natural gas line to each burner is equipped with a shutoff valve. Initially both valves were fully open and the burners were presumed by UMC staff to be operating at equivalent firing rates and stoichiometries. We could not independently verify this assumption. The left-hand burner valve was then progressively closed. Ultimately, the total fuel flow to the furnace was seen to decrease. Then the left-hand burner valve was opened fully and the right-hand burner valve was progressively closed. 
These large burner fuel flow changes could readily be observed in the parameter values plotted for the two burners on the UMC computer. Given that the furnace was operating in soak mode at very high excess air levels, reducing the fuel flow to a particular burner would only make its operation even leaner. It was not clear whether the differences highlighted by the UMC staff related to differences in burner stoichiometry or differences in burner firing rate.

\subsection{Heat-up Period Optimization - Third Attempt}

The ability of the manual air damper movement to affect a greater change in burner stoichiometry at high firing rates was improved by disabling the furnace's ratio regulator. This regulator was determined to be moderately effective when the burners were operating at high fire, but ineffective at medium to low fire conditions. Nonetheless, this regulator was preventing the achievement of a real modification in burner stoichiometry at high fire when the FIA system was being tested. Accordingly, the furnace fuel train was modified before the next day's testing to ensure that the ratio regulator was fully open at all times.

The first test of the next day, Run \#16, was conducted with the ratio regulator forced fully open. In this mode it was possible to control the burner stoichiometry over a wide range. As shown in Figure 17, the furnace flue gas oxygen level was changed from $\sim 3 \%$ to $0 \%$ as the air damper was progressively closed during FIA testing. When the air damper was moved to the $12.5 \%$ open position, the flue gas oxygen fell to zero and the carbon monoxide level went off-scale, indicating that the burners were operating at fuel-rich conditions.

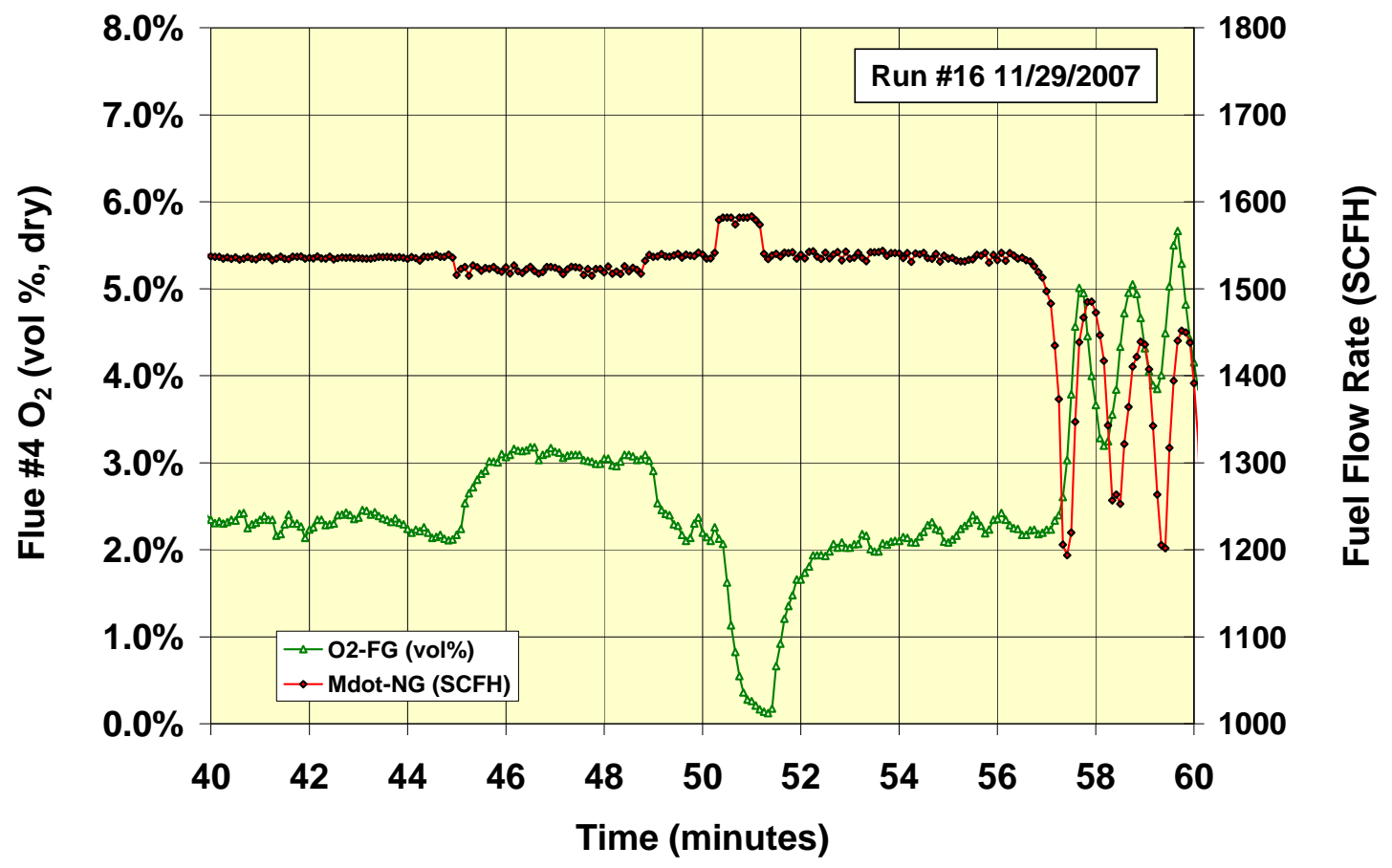

Figure 17. Fuel flow and flue \#4 oxygen data for FIA test with fuel/air ratio regulator fully open. 
The FIA parameter of interest was observed on the UMC computer screen during this test period and again showed a monotonic increase with time. Despite the fact that the burners were shifted from $\sim 15 \%$ excess air operation to fuel-rich operation, no maximum in the parameter of interest was noted.

\subsection{Heat-up Period Optimization - Fourth Attempt}

One additional optimization test was conducted during the heat-up period with the ratio regulator returned to normal operation. Once again, no maximum in the parameter of interest was observed.

In conclusion, UMC staff did not demonstrate the ability of the FIS instrument to identify an optimum furnace operating condition. Consequently, no additional energy consumption data were obtained.

\section{Summary of Results}

Baseline testing indicated that the furnace was operating at very high excess air levels for much of the three hour load cycle. Alternative baseline testing showed that, within the operating constraints of the currently installed equipment, energy savings of 15 percent were possible. Additional savings would require modification of the burner control system.

In practice, the furnace operators were uncomfortable with routinely using manual adjustments of the air damper at different phases of the load cycle to reduce fuel use, as the potential exists for operator error. However, moving the default fixed position of the air damper from the $40 \%$ open setting to the $25 \%$ open setting was an acceptable option, and yielded an energy saving of approximately 7 percent (according to the furnace operator), while producing consistently good quality parts. This setting had been reached by UCM and Missouri Forge staff through prior testing.

The performance of the FIA system during the V\&V project testing was disappointing. The operators of the system were unable to detect an optimum condition based on their flame analyses. Consequently, no energy efficiency benefit relating to use of the FIA system could be assessed. Differences between signals from the two burners when they were deliberately put out of balance were observed. However, it was not clear whether there is adequate sensitivity to effectively balance multi-burner furnaces. 


\section{Market Implications of the Test Results}

During the V\&V testing, the FIA system failed to deliver on the key benefit claimed: the ability to diagnose conditions in an operating furnace and optimize burner parameters for peak energy efficiency. No market exists in risk-averse manufacturing industries for capital equipment that does not yield tangible and reliable benefits. Even if the FIA system had been able to inform the operators of optimum settings, the system would have to demonstrate a competitive advantage over conventional approaches (e.g., using portable flue gas analysis equipment to tune combustion equipment for optimum efficiency and emissions) in order to attract sales. 


\section{Appendix: Test Plan Prepared by UMC \\ Flame Image Analysis (FIA) Tests \\ (Real-Time) \\ November 2007}

\section{TEST \# 1 COMBUSTION OPTIMIZATION}

\section{Background}

The furnace currently has a fuel flow meter. The air flow rate control is by adjustment of a butterfly damper using a handle. The air flow is shown in percent (\%) where $40 \%$ is maximum air flow rate.

The first hour of each 3-hour batch heating process is for heating the furnace to reach the desired temperature. During the first hour air flow is set at $40 \%$ and the fuel flow is at maximum.

The remaining 2 hours are for heating the load at a set temperature. The air flow rate is at $40 \%$ and the furnace control system controls the fuel rate to keep the temperature at the desired set point.

Thus for this furnace the combustion optimization should provide the highest heat generation during the first hour and minimum fuel consumption during the remaining 2 hours.

\section{OPTIMUM AIR FLOW RATE FOR COMBUSTION OPTIMIZATION}

This test has two subtests:

A) Test A will be for optimum air flow for the first hour heating time when furnace is heated with both burners' fuel handle fully open and maximum total fuel rate to reach the desired temperature within one hour.

B) Test B will be for optimum air flow for the remaining 2 hours of soak time when the control system will control the total fuel rate in order to keep the furnace at the desired temperature.

\section{$\underline{\text { TEST A }}$}

Combustion optimization during the first hour is based on air/fuel ratio that provides the highest energy production and hence, minimum time to reach the desired temperature. In this test the system will show and select the optimum air flow. Begin the test before the end of heating time. This test would not take more than 5 minutes: 
1. Start with air flow rate of $40 \%$ setting, and decrease the flow rate until the system would say "OPTIMUM" on its monitor.

2. Start with air flow rate of Minimum setting, and increase air until the system would say “OPTIMUM” on its monitor.

\section{$\underline{\text { TEST B }}$}

This test is performed while system is on automatic control. Air flow rate is set at the selected optimum during the first hour test. The control system has no influence on air flow rate; it only controls the fuel flow rate in order to keep the temperature constant. Begin the test about 15 minutes before the end of cycle in order to avoid load heating uproar. In this test the system will show and select the optimum air flow.

Begin with setting air at highest flow rate (i.e., 40\%) and decrease air flow rate gradually while checking the system looking for "OPTIMUM" sign on the monitor.

\section{TEST PROCEDURE ON WEDNESDAY}

Batch 1: Conduct flame image analyses at two points in time within the 180 min heat treating cycle (40 and 160 minutes). These points in time should correspond to the highest and lowest burner firing rates, under normal operation. For each analysis, the air damper will be adjusted to 5 different positions. Each position will be held for about 5 seconds. These results will be evaluated to define the optimum air damper position(s) for the next two batches.

Batch 2: Operate the furnace using the recommended air damper settings from the Batch 1 analyses. Monitor fuel consumption and flue gas composition.

Batch 3: Same as Batch 2. Duplicate test for assessment of batch-to-batch variability.

\section{TEST \# 2 BURNER BALANCING}

Perform this test during soak time after the first hour of heating period in order to avoid furnace disturbance during operation. Although, there is a flow meter for the total fuel flow rate there is no flow meter for individual burners. The fuel flow rate can be changed in each burner using a handle. With the manual handle it is not known how much fuel rate is changed in each burner. For this reason when both burner's fuel handle are fully open establishes the best balanced condition ${ }^{4}$.

\footnotetext{
${ }^{4}$ Since there is no individual flow meter for each burner, therefore setting both handles at any seemingly equal position does not guarantee an accurate balanced position. Hence, only when the handles are fully open for both burners can be considered the best balanced position.
} 
This test can be performed at any selected total fuel level. Burner control will be on manual and the selected total fuel level will remain constant during the test.

Choose a fuel level and start the test with both burners fully open:

1. Change burner handle for either of burners to increase or decrease fuel rate to that burner. The system would tell which burner fuel rate was changed and whether the change was upward or downward.

2. When both burners are in balanced position the system will recognize the burners are balanced.

Select another total fuel rate and repeat the test.

\section{TEST PROCEDURE ON THURSDAY}

Batch 4: Conduct flame image analyses at three points in time within the 180 min heat treating cycle (60, 80, and 100 minutes). These points in time should correspond to key intermediate burner firing rates, under normal operation. For each analysis, the air damper will be adjusted to 5 different positions. Each position will be held for about 5 seconds. These results will be evaluated to define the optimum air damper position(s) for the next batch.

Batch 5: Operate the furnace using the recommended air damper setting(s) from the Batch 4 analyses. Monitor fuel consumption and flue gas composition.

Batch 6: Conduct burner balancing tests during the 140 - 180 minute period. Adjust the fuel flow to one burner while monitoring with the imaging system. Determine if the system is capable of detecting the changes and guiding the fuel flow back to the original rate. Conduct three separate tests, each having a different initial deviation in fuel flow. Repeat the test series with the other burner.

Friday: Contingency for additional tests to complete any incomplete tests from Wednesday or Thursday. 

Appendix B

Test Summary from Enterprise Energy and Research July 2008 



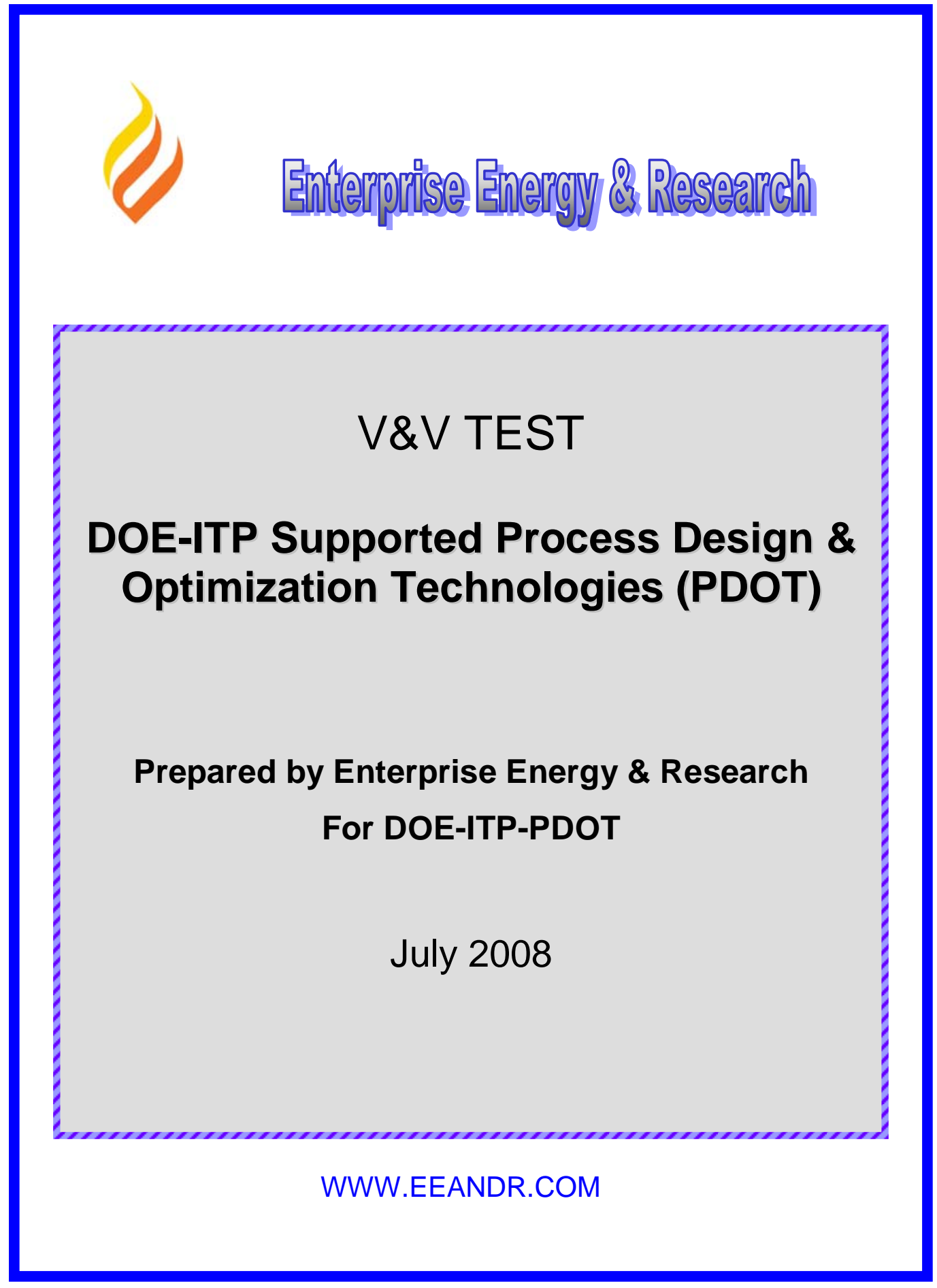





\section{Table of Content}

Page

Preface $\quad 2$

Summary 3

FIA versus Flue Gas Analyzer 5

EE\&R Report on V\&V test $\quad 7$

Attachment Energy Savings $\quad 11$

Furnace Internal Images by FIA camera:

$\begin{array}{ll}\text { Figure } 1 & 7\end{array}$

Figure $2 \quad 8$

Figure $3 \quad 10$

Appendix-1 FIA Optimization Plot (Figure 4) 14 


\section{Preface}

It is possible to achieve a more economical and less polluting production in the U.S. manufacturing sector through the adoption of advanced technologies that help reduce energy consumption and emissions.

Improved combustion analysis \& control via flame monitoring allows a gas fired furnace to operate at its practical optimum combustion, reduced fuel consumption, and reduced excess air levels resulting in improved system efficiency in addition to lower NOx emissions.

Advanced information processing techniques when integrated with artificial intelligence, behave as "virtual sensors" to extract information from the images of flames. These "sensing" functions -also called flame monitoring- enable better control of gas-fired furnaces.

The technology behind the sensor is resulted from the integration of vision technology and artificial intelligence while utilizing techniques derived from computer graphics, image processing and enhancing, image analysis, data mining, as well as mathematical modeling and feature extraction techniques in order to monitor flame and detect its realtime properties. At the heart of this sensor is a Flame Image Analyzer (FIA). A computer and a water-cooled periscope-based camera that withstands temperatures up to $3500^{\circ} \mathrm{F}$ constitute the hardware of the sensor.

It is anticipated that this sensor will offer great potential for improving furnace thermal efficiency and lowering NOx emissions. Evaluating the performance of this sensor requires its installation and testing in a host industrial furnace and comparing the energy consumption before and after installation. The host plant selected for commercial demonstration is the ArkMO heat treating division of Missouri Forge (MOFORGE) located in Doniphan; 270 miles south of St. Louis, Missouri.

A new Initiative was launched in 2006 by the Department of Energy which is referred to as DOE-ITP-supported Process Design \& Optimization Technologies (PDOT). Through this Initiative the DOE would provide support for an independent contractor to perform a Verification and Validation (V\&V) of the selected technologies. The FIA was one of the two finalists that were selected for $V \& V$ tests based on the following two criteria:

(1) Commercialization potential of technology and the associated market barriers

(2) Potential cost savings and cost barriers associated with the technology

The objective of this report is to provide all the available information on the energy savings as a result of installation of this FIA sensor at the host furnace. In addition, FIA performances associated with the $V \& V$ process are explained in details in order to provide a comprehensive documentation of the $\mathrm{V} \& \mathrm{~V}$ test for this project.

This document provides information on energy savings reported by the MOFORGE furnace operator as a result of installation of FIA, a comparison of FIA and flue gas analyzer capabilities for optimization of this furnace, and a report on $V \& V$ test by Enterprise Energy \& Research (EE\&R). 


\section{SUMMARY}

The Flame Image Analyzer (FIA) was selected by the Department of Energy -Industrial Technology Program (DOE-ITP) for Verification and Validation (V\&V) test in the first series of DOE-ITP-supported PDOT in 1996.

The tests to be verified and validated for FIA were: a) Optimization and b) Burner Balancing capabilities of FIA system.

The MOFORGE host furnace is a heat treating furnace that operates on a 3-hour cycle for heating of each load. The first hour (high fire period) is to heat up the furnace (after the load is placed in the furnace) to $1650^{\circ} \mathrm{F}$. To reach the desired temperature as quickly as possible the fuel valve is fully open and the air valve (butterfly valve) is set at $40 \%$. To prevent fuel rich condition, the furnace is equipped with a ratio regulator that reduces fuel as air is reduced. Under this condition it takes one hour to reach the desired temperature. The optimization in this period would result in reaching the desired temperature in less than one hour. Hence the energy savings are achieved by both:

$>$ Combustion Optimization

$>$ Heating Time Reduction

The objective for optimization in the remaining two-hour soak period of the cycle is to burn minimum fuel while sustaining the desired temperature of $1650{ }^{\circ} \mathrm{F}$ during the entire soak period.

\section{Summary of Results:}

a) Optimization: For the MOFORGE host furnace the optimization was evaluated for three periods of $1^{\text {st }}$ (high fire), $2^{\text {nd }}$, and $3^{\text {rd }}$ (soak period) hour.

- The on-line (not in real-time) optimization of first hour had been successfully performed by FIA prior to November 28, $2007 \mathrm{~V} \& \mathrm{~V}$ test and the furnace has been operating with $25 \%$ air setting according to FIA optimization ever since. This is also

mentioned in the Environ V\&V report under section "8. Summary of Results".

However, the first hour optimization could not be observed in real-time during the test on November 28 and 29, 2007 (see section 2. Optimization on page 9).

- The FIA optimization in real time was successfully observed in both $2^{\text {nd }}$ and $3^{\text {rd }}$ hour by all major participants and is explained in the attached file entitled "EE\&R REPORT ON V\&V TEST". Appendix-1 provides information on how this furnace was optimized during the soak period prior to November 28, $2007 \mathrm{~V} \& \mathrm{~V}$ test.

b) Burner Balancing: This test was composed of two parts: 1) FIA Burner Balancing Capability Test, and 2) Sensitivity Test. 
1) FIA passed these entire tests as explained in the attached file entitled "EE\&R REPORT ON V\&V TEST", and in Environ V\&V report under burner balancing section.

2) Lack of individual burner fuel flow meter turned out to be a limiting factor for this test. As a result, the test could not establish the maximum sensitivity or minimum recognizable flow rate change as explained in the attached file entitled "EE\&R REPORT ON V\&V TEST" and in Environ V\&V report under burner balancing section.

The FIA furnace optimization for the soak period is explained in Appendix-1 (performed prior to November 28, $2007 \mathrm{~V} \& \mathrm{~V}$ test).

The measured energy savings of FIA system was 7.4\% as reported by the furnace operator with data presented in the attachment entitled Energy Savings. As the data in the attachment shows, the fuel consumption is measured at the end of each hour. Hence, this saving does not take into account the time reduction to reach the desired temperature of $1650^{\circ} \mathrm{F}$. 


\section{FIA versus flue gas analyzer}

\section{Optimization}

This section addresses the FIA optimization of this furnace for the first hour of high fire operation and provides information as to why flue gas analyzer can not perform such a task.

Only FIA could have optimized this furnace during its first hour of operation which accounts for $47.5 \%$ of the total energy consumption of a 3-hour run according to table 5 of Environ V\&V report. In fact, FIA needed only one second of time to collect the required data for optimization.

How could the flue gas analyzer optimize the furnace during the first hour of high fire (as reported in table 2 test \# 12 in Environ V\&V report)?

One way to optimize would have required running the furnace manually during the first hour, reducing the air, and adjusting the fuel similar to experiment \#10 of Environ V\&V report. However, this was impossible due to the following reasons:

1. Reducing the air would trigger the furnace ratio regulator to reduce the fuel rate as well (in order to prevent fuel rich condition)

2. This is the heat up period where the furnace must be heated as quickly as possible to the desired temperature $\left(1650{ }^{\circ} \mathrm{F}\right)$. Therefore, contrary to experiment \#10 there is no set constant temperature to give guidance on how much to adjust the fuel. The fuel valve is wide open in this period.

3. Fear of high temperature damage to the baffle (see Environ V\&V report)

Another way would be to guess a good number for excess $\mathrm{O}_{2}$ such as $3 \% \mathrm{O}_{2}$ in the flue gas on page 15 of Environ V\&V report. However this would not provide optimization for this furnace as explained below:

Reducing air in the first hour to achieve $3 \% \mathrm{O}_{2}$ in the flue gas (compared to average of $5 \%$ for all flue ports: page 15 of Environ $V \& V$ report) is quite different from FIA optimization of $25 \%$ air for first hour of operation. Note from figure 16 on page 20 of Environ $V \& V$ report that flue port \#4 shows about 3.6\% excess $\mathrm{O}_{2}$ at optimum air of $25 \%$ by FIA. Considering this flue port had the lowest excess $\mathrm{O}_{2}$ of $2.2 \%{ }^{5}$ (see table 3 of Environ $\mathrm{V} \& \mathrm{~V}$ report), reducing the average flue gas $\mathrm{O}_{2}$ from $5 \%$ to $3 \%$ means a much less value than $2.2 \%$ for port \#4. Therefore, $25 \%$ air as optimized by FIA does not correspond to the required excess $\mathrm{O}_{2}$ of page 15 of Environ $V \& V$ report. According to this required excess $\mathrm{O}_{2}$ the furnace

\footnotetext{
${ }^{5}$ Yet, figure 9 shows the same port \# 4 with an excess $\mathrm{O}_{2}$ of much above $5 \%$ during the first hour. So how reliable is this method for optimizing the furnace during first hour?
} 
air setting should be below $25 \%$.

Therefore, it is not clear how flue gas has suddenly optimized this furnace at $25 \%$ air setting in table 2, test \#12 with no further explanation of this test in the Environ V\&V report.

In addition, clearly experiment \#10 in Environ V\&V report has nothing to do with flue gas monitoring system capability. It was an experiment performed manually during the 2nd and $3 r d$ hour when the system temperature must remain at a set point $\left(1650{ }^{\circ} \mathrm{F}\right)$. Therefore, by reducing air one reduces the fuel while watching the temperature and adjusting fuel to make sure the temperature stays constant. Where is the role of flue gas monitoring here? There is no need for flue gas monitoring to measure the energy savings. The operator could have done that in similar fashion as the attached data (in the attachment entitled Energy Savings) which were measured by the furnace operator to report the $7.4 \%$ energy savings of FIA optimization.

Furthermore, since one can not reduce the air below $12.5 \%$ without tripping the furnace, setting the air at $12.5 \%$ by FIA $^{6}$ at the beginning of the soak period would result in less fuel consumption as compared to manually reducing air and adjusting fuel as measured by Environ on page 16 . The $15 \%$ savings of the Environ V\&V report ${ }^{7}$ is based only on one experimental data from test \#9 compared with one experimental data of test \#10. Table 5 of Environ $V \& V$ report shows the energy savings of baseline varies $6.7 \%$ between minimum and maximum savings. The furnace operator data (in the attachment entitled Energy Savings) clearly shows the variations in fuel consumption from experiment to experiment. Thus, if one only relies on one experimental data, then the FIA energy savings can reach as high as $17.86 \%{ }^{8}$ without taking into account the energy saving due to time reduction in reaching the set point $\left(1650^{\circ} \mathrm{F}\right)$ in the optimized first hour operation.

\section{FIA \& Flue gas analyzer}

In response to item "9. Market Implication of the Test Results" of the Environ V\&V report, it should be mentioned that there are numerous advantages of FIA system over flue gas analyzer. Some of its advantages are far beyond the limited capability of flue gas analyzer. A few examples are provided below:

1. FIA is so versatile that it can be adapted to optimize a variety of furnaces according to their specific requirements. For example, in this furnace FIA takes into consideration both the excess air (i.e., air/fuel ratio) and the heat generation necessary to prevent cooling of the furnace during the first hour. Therefore, an

\footnotetext{
${ }^{6}$ FIA data showed little would be gained by air below $12.5 \%$ when compared with $15 \%$ air in amplitude of fluctuations for the two air settings. Therefore, $12.5 \%$ minimum air setting was considered the possible optimum value.

${ }^{7}$ Note this is savings only for the second and third hour of operation as in this experiment no change was made to the first hour of automatic operation.

${ }^{8}$ choosing the highest for $40 \%$ air and the lowest case for $25 \%$ air (1st hour) and add to it the savings of $12.5 \%$ air of 2 nd \& 3rd hour ([28-23]/28).
} 
optimum condition for this furnace could not be achieved based on stoichiometry of air/fuel ratio alone. The flue gas analyzer only relates the emission products to excess air in search of stoichiometry of air/fuel ratio, which is not sufficient here.

2. FIA does not have any problem with accuracy while flue gas analyzers do. Flue gas analyzers only collect a small potion of the total flue gas and then rely on further estimations and averaging that are introduced in the calculations as presented in the Environ V\&V report.

3. FIA looks at the source not end product emission like flue gas analyzer.

4. FIA system is uniquely user friendly without requiring any analysis by the FIA operator.

5. FIA's speed is unbeatable.

\section{EE\&R REPORT ON V\&V TEST \\ On November 28-29, 2007}

\section{Major Participants:}

Oakridge National Laboratory: Daryl Cox

Environ: Charles Benson

MOFORGE: Gary Pennington

EE\&R: Shahla Keyvan

\section{Background}

This report is a summary of the tests and events during the two days of $\mathrm{V} \& \mathrm{~V}$ testing on November 28-29, 2007 at MOFORGE furnace.

Based on the Flame Image Analyzer (FIA) optimization the furnace has been operating at its best optimum condition since October 2007. The total energy savings of $7.4 \%$ is reported by the MOFORGE furnace operator.

Figure 1 shows the FIA camera image of the inside of the upper section of the furnace that houses the two burners. Figure 2 is the camera images taken from outside of the furnace showing the furnace interior with and without the load. 


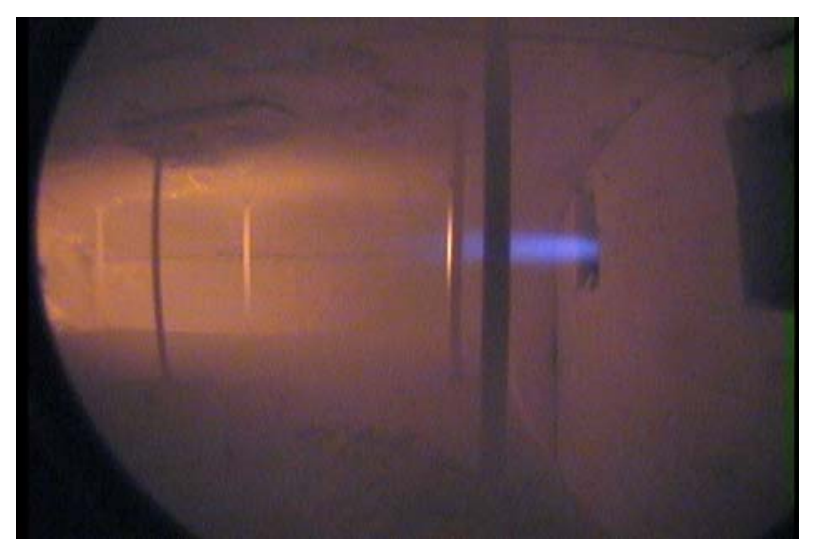

Figure 1. Upper chamber of the furnace as viewed by the FIA camera

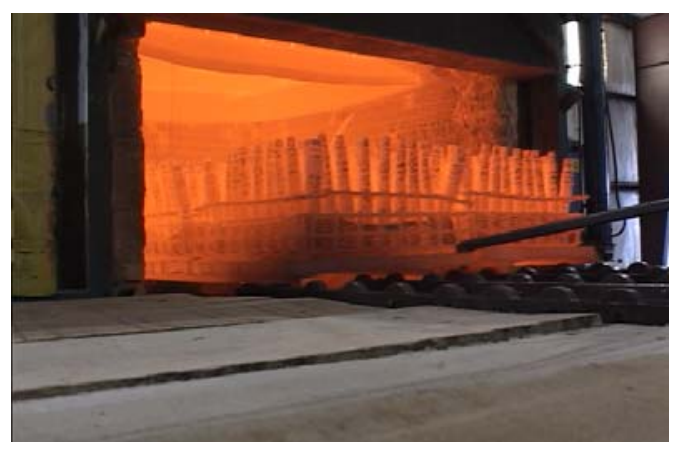

(a)

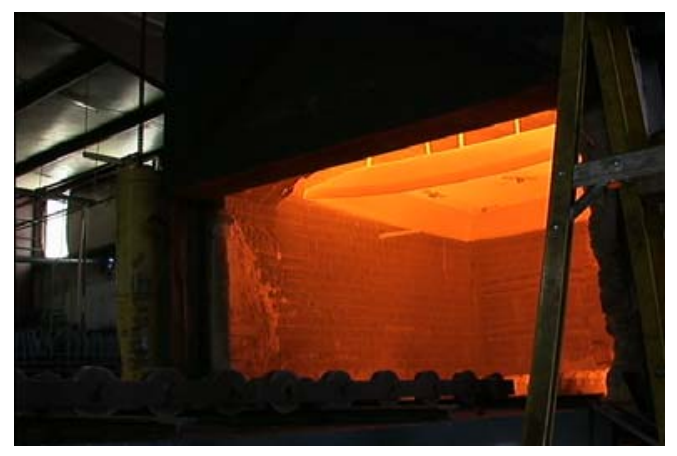

(b)

Figure 2. a) Furnace interior as load is being removed, b) Furnace interior without load

\section{$\underline{11 / 28 / 07}$}

A summary of the tests performed are presented below.

1. Test 1 to check optimization on high fire period. This test was discontinued at $15 \%$ air flow since the furnace air flow meters could not continue beyond $15 \%$. At 10:30 AM the test started with air setting at:

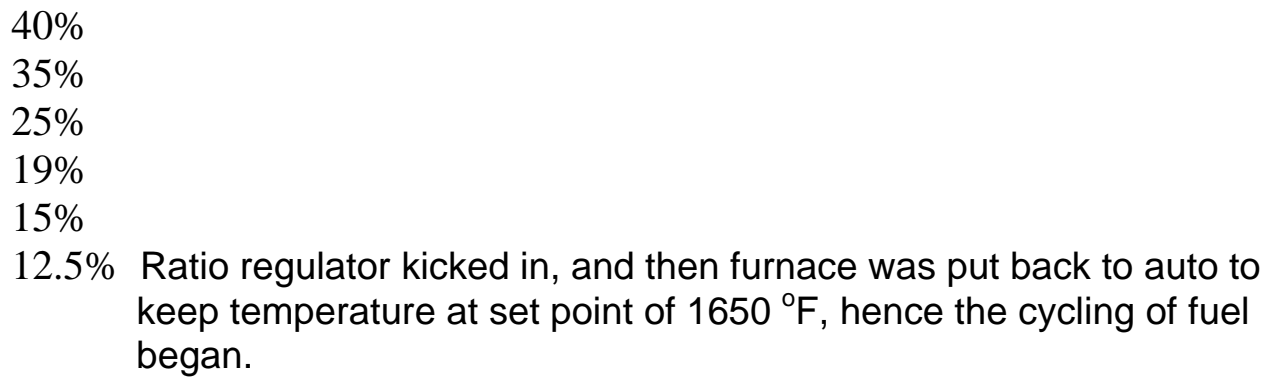


2. Test 2 was carried out to verify the $12.5 \%$ optimization of FIA for $2^{\text {nd }}$ hour of heating.

In the morning of the test EE\&R explained to Environ that the word "OPTIMUM" will not appear on the monitor for optimization during $2^{\text {nd }}$ and $3^{\text {rd }}$ hour. It was made clear that the amplitude of the fluctuations will decrease as air is reduced during soak time, and the optimum is when minimum amplitude is reached. It was accepted by Environ to look for the minimum fluctuations on FIA monitor instead of the word OPTIMUM.

FIA showed minimum fluctuations in its plotted parameter and passed the test as was observed by Environ

At about 11:20 a.m., started the test with air at:

40\% FIA monitor showed "reduce air" command all the way until 12.5 $\%$ air

$25 \%$

$15 \%$

12.5\% Minimum fluctuation as compared to previous air settings

3. Test 3 was carried out to check optimization of high fire period. Since this test started at 13:40 PM with temperature too low $\left(T=1545^{\circ} \mathrm{F}\right.$ far below stabilized $1650{ }^{\circ} \mathrm{F}$ ), it was dismissed.

4. Test 4 was carried out to verify the $12.5 \%$ optimization of FIA for $3^{\text {rd }}$ hour of soak period. FIA passed the test as was observed by Environ by showing minimum fluctuations in its plotted parameter at $12.5 \%$ air (see Appendix-1 for optimization of FIA for $3^{\text {rd }}$ hour of soak prior to $\mathrm{V} \& \mathrm{~V}$ test)

5. Test 5 was carried out to perform burner balancing. FIA passed every test requested by Environ. See details below under burner balancing.

\section{$\underline{11 / 29 / 08}$}

1. Test 1 was carried out to check optimization on high fire with ratio regulator bypassed. At 10:40 AM the test was started with air at:

$40 \%$

$25 \%$

$12.5 \%$ This test was abandoned due to Fuel surge as a result of bypassing ratio regulator.

2. Test 2 was carried out to check optimization of high fire with ratio regulator back in place. At 2:00 PM the test was started with air at:

$40 \%$

$25 \%$

$12.5 \%$ Ratio regulator kicked in, and furnace was put back to auto to keep temperature at set point of $1650^{\circ} \mathrm{F}$. Hence, the cycling of fuel began. See the FIA system parameter plot under optimization below (Figure 3 ). This plot shows that at $12.5 \%$ heat generation starts to decrease (after $\sim 2$ minutes), thus FIA 
would select the previous air setting of $25 \%$ as optimum.

Since it was not possible to observe this decrease in the FIA variable instantly, this was reported by Environ as FIA did not pass the test.

The only issue here is that for this application and optimization it requires a few minutes until FIA can verify the decrease in heat production as air is reduced.

\section{Burner Balancing}

Since there was no air flow meter, the initial condition with air valves of both burners fully open with equal air going to each of them was considered a "reference balanced condition". The FIA identified every other condition as the air was changed in both burners, and further identified which burner was changed.

Burner balancing was performed for various conditions and FIA passed all those tests as was confirmed by Environ during these tests. At the end of these tests, it was discussed between EE\&R and Environ that the furnace was not able to provide flow rates information on each individual burners so that a test for optimum sensitivity (i.e., what is the smallest difference between the 2 burners that FIA can recognize) is not possible.

\section{Optimization}

In the morning of 11/28/07 it was explained to Environ that the word "OPTIMUM" will not appear on the monitor for optimization rather, instead the word "reduce air" would appear on monitor if air needs to be reduced further after each air setting from $40 \%$ down. In addition, the parameter being plotted would increase as it says "reduce air" until where the parameter no longer increases rather starts to decrease, which means the prior air setting (not the present one that caused the decrease in parameter value) is the optimum.

This parameter is indirectly proportional to both excess air and heat produced in the furnace. Thus FIA follows two variables, one for air/fuel ratio or excess air and the other for heat generation. That is why FIA can optimize this furnace since; not only one wants to minimize the excess air but also must make sure the proper heating of the furnace continues. That is why an air setting selected based on FIA "reduce air" can still be rejected by FIA and replaced by previous air setting due to decrease in the value of the parameter which indicates that enough heat is not generated.

The only phenomenon that was not possible to observe was seeing the decrease in the FIA variable instantly. However, it takes a few minutes until FIA can verify the decrease in heat production as shown in Figure 3 below. In this plot, the first 25 second of purple color is $25 \%$ air and the rest is at $12.5 \%$ air similar to yellow color. The cycle in yellow decreases as indicated by the two red parallel lines enclosing the upper and lower part of the cycle. In the absence of heat reduction, the red lines would have been horizontal (see figure 4 in Appendix-1). Thus, 12.5\% air is not sufficient air for the first hour optimization. 


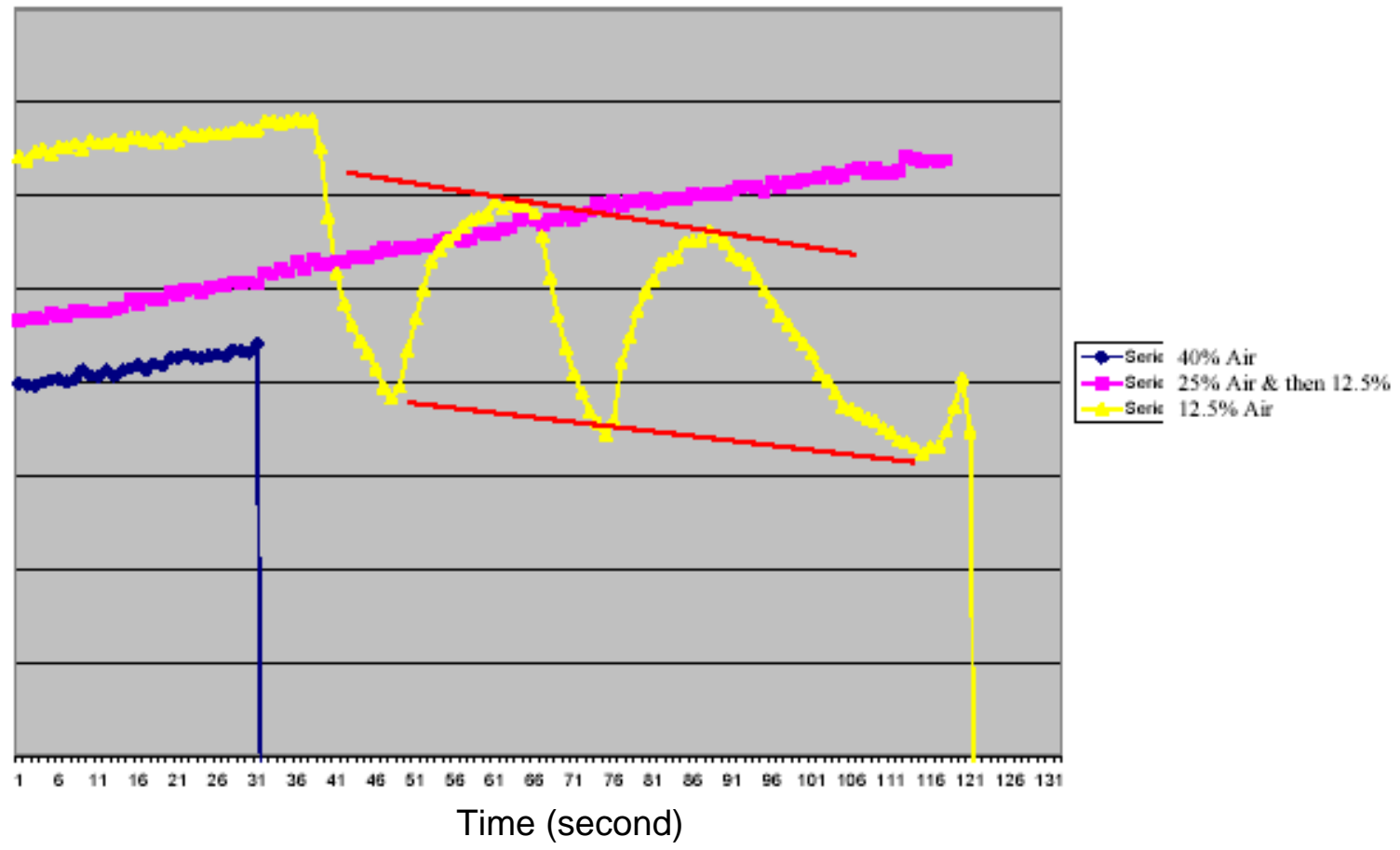

Figure 3. FIA data during optimization in the first hour heating period

Furthermore, the plot of Figure 4 in the Appendix-1 shows how FIA was able to select the optimum air during the soak period. In addition, this plot shows the cycling data are horizontal since there is no heat reduction confirming the claim in the above statement of yellow cycling of Figure 3.

\section{ATTACHMENT \\ Energy Savings}

Data Collected by the MOFORGE Furnace Operator 


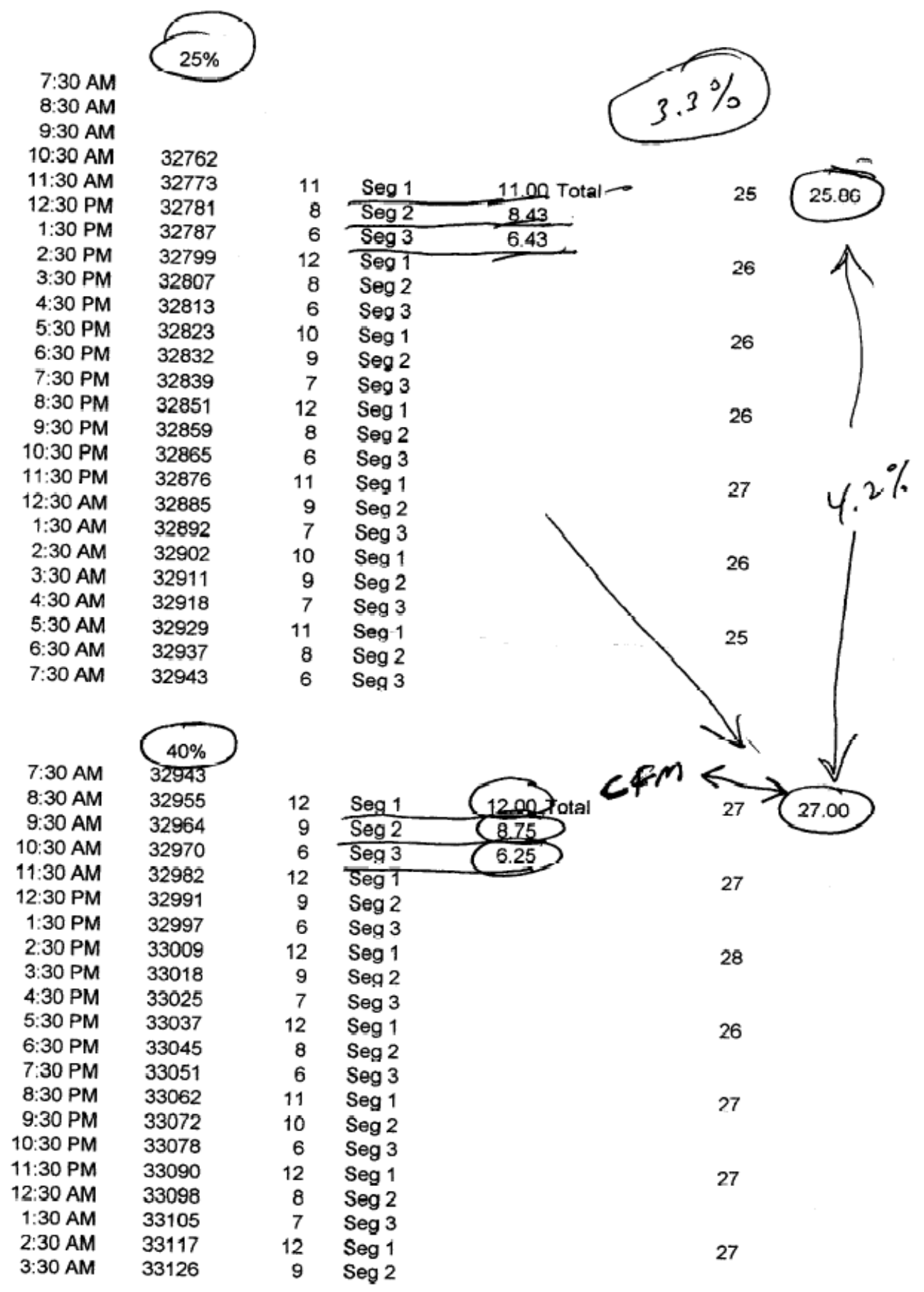




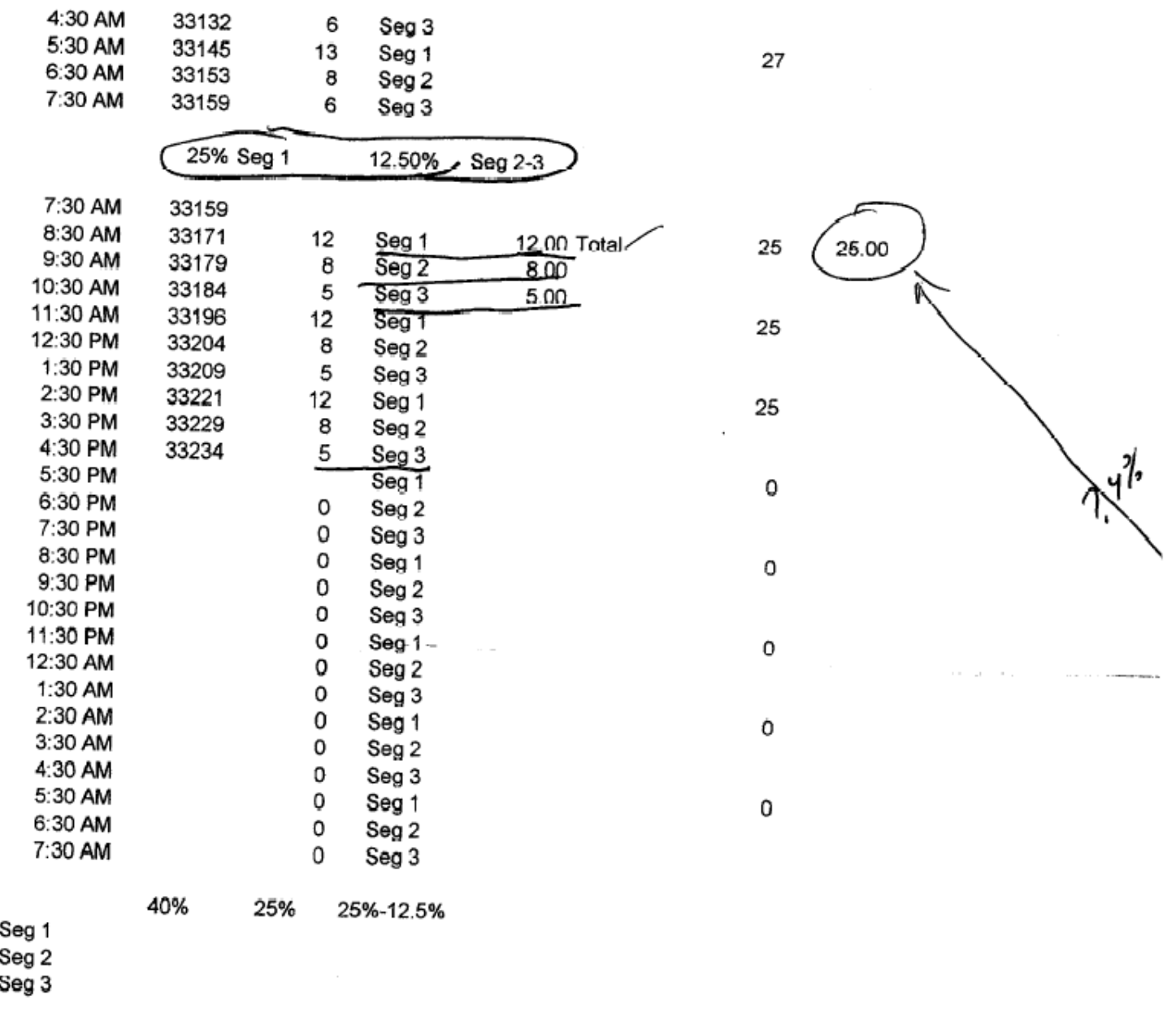




\section{APPENDIX-1}

To follow the logic of how FIA optimizes this furnace see Figure 4 which shows a plot of data obtained during optimization of the soak period prior to $\mathrm{V} \& \mathrm{~V}$ test. This plot shows why $12.5 \%$ air is selected by FIA as the best possible optimum air for the soak period optimization. As seen in the plot reducing air from $40 \%$ (red plot) to $25 \%$ (cyan) has no effect on the amplitude of fluctuation in the data. The data plotted are indirectly related to the heat production in the furnace. Comparing $15 \%$ air to $12.5 \%$ shows small improvement by going to $12.5 \%$ air. Since furnace design does not allow operation below $12.5 \%$ and since reduction from 15\% (blue plot) to $12.5 \%$ (green plot) yields a very small improvement, thus the $12.5 \%$ was selected as the optimum air flow during soak period.

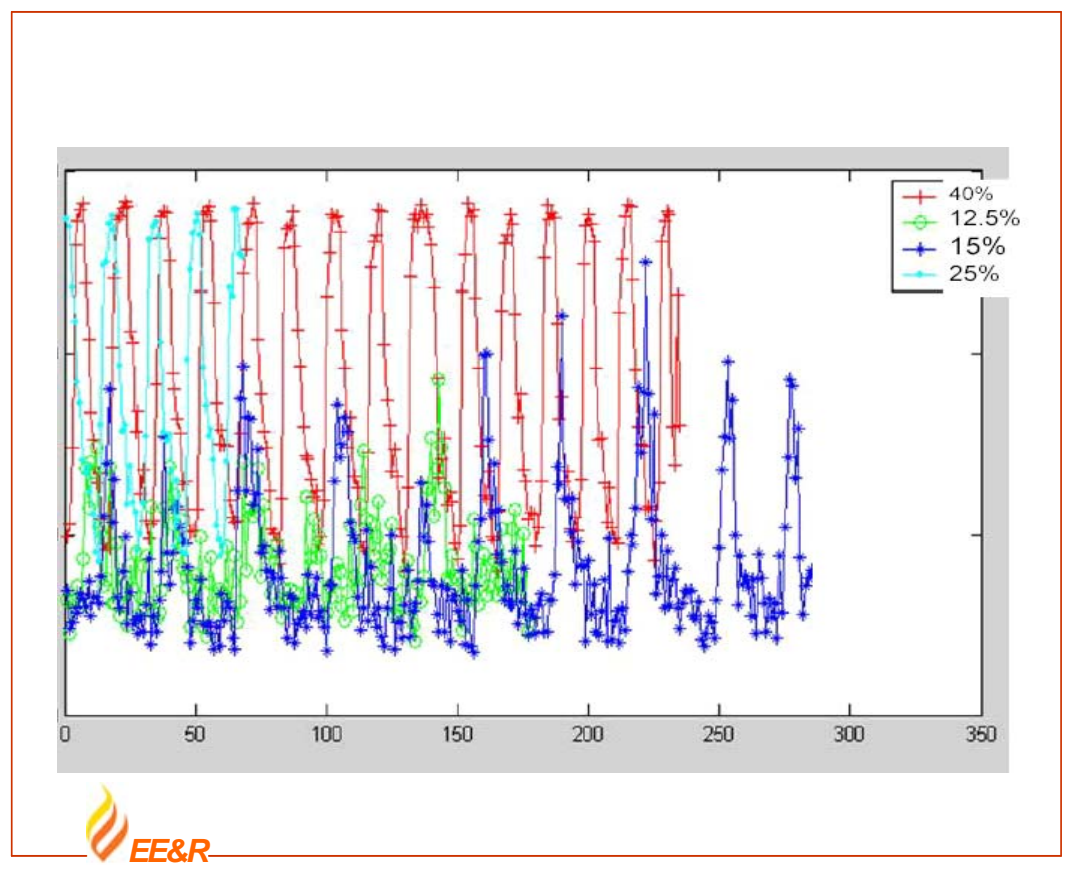

Figure 4. Plot of FIA data during $3^{\text {rd }}$ hour soak period 